\title{
Gasto fiscal e inversiones en mano de obra libre en Hispanoamérica. El caso de Cartagena de Indias (1750-1810)*
}

\section{Resumen}

En el marco de los recientes debates sobre la naturaleza de la monarquía y del imperio español, el Estado fiscal militar y las características del gasto fiscal, este artículo presenta algunas ideas sobre la historiografía que se ha referido a algunos temas que de alguna forma tocan aspectos relacionados con las inversiones en las colonias y con la demanda de mano de obra por parte de las instituciones de la corona. Me interesa ver, por una parte, en qué medida esos estudios modifican una larga tradición historiográfica sobre las relaciones entre la corona española y sus posesiones en Hispanoamérica, y, por otro lado, como el caso de Cartagena de Indias se ubica en estos debates y cómo puede ayudar a comprender de mejor forma, y a nivel de una localidad, algunas consecuencias sociales de las reformas borbónicas.

\section{Palabras clave}

Tesauro: Cartagena de Indias, reformas borbónicas, gasto fiscal, sistema de defensa, trabajadores, inversiones, salarios.

Referencia bibliográfica para citar este artículo: Sergio Paolo Solano D. "Gasto fiscal e inversiones en mano de obra libre en Hispanoamérica. El caso de Cartagena de Indias (1750-1810”. Anuario de Historia Regional y de las Fronteras, 24.2 (2019): 195-232.

Sergio Paolo Solano D: Profesor titular Programa de Historia, Universidad de Cartagena. Candidato a doctor en Humanidades-línea Historia, Universidad Autónoma Metropolitana-unidad Iztapalapa (México). Ha dirigido la revista El Taller de la Historia (Universidad de Cartagena), y forma parte de su comité editorial. Es miembro de los comités científicos de las revistas Boletín Americanista (Universidad de Barcelona, España), Memorias (Universidad del Norte, Colombia) y Amauta (Universidad del Atlántico, Colombia). Investiga temas de historia social y política de Latinoamérica, siglos XVIII y XIX. Integra el grupo de Investigaciones Historia Económica, Social y Política (H-ESOPO) del Programa de Historia de la Universidad de Cartagena. Código ORCID: 0000-0003-1180-8163. Correo electrónico: ssolanod@unicartagena.edu.co.

\footnotetext{
* Este artículo es producto de una investigación desarrollada en el marco del Programa de Estudios Coloniales del Laboratorio de Investigación Histórica en Estudios Coloniales de la Universidad de Cartagena, que se lleva a cabo a través del convenio entre el Grupo de Investigación en Historia Económica, Social y Política (H-esopo) del Programa de Historia de esta Universidad y Cartago Fundation de Suiza. Un resumen del artículo fue presentado como conferencia inaugural en el VII Simposio Colombiano de Historia Regional y Local, organizado por la Asociación Colombiana de Historia Regional y Local y la Escuela de Historia de la Universidad Industrial de Santander, Bucaramanga, octubre 29 y 30 de 2018. Expreso mis gratitudes para con los colegas Alfonso Fernández Villa y Ana Milena Rhenals, profesores de esta Universidad.
} 


\title{
Tax Expenditure and Investments in Free Labor in Latin America. The Case of Cartagena de Indias (1750-1810)
}

\begin{abstract}
Summary
In the framework of the recent debates on the nature of the monarchy and the Spanish empire, the military fiscal state and the characteristics of fiscal spending, this article presents some ideas on historiography that has referred to some issues that in some way touch on aspects related to investments in the colonies and with the demand for labor by the crown institutions. I am interested to see, on the one hand, to what extent these studies modify a long historiographical tradition about the relations between the Spanish crown and its possessions in Spanish America, and, on the other hand, as the case of Cartagena de Indias is located in these debates and how can it help to better understand, and at the level of a locality, some social consequences of the Bourbon reforms.
\end{abstract}

Keywords

Thesaurus: Cartagena de Indias, Bourbon reforms, Fiscal spending, Defense system, Workers, Investments, Salaries.

\section{Despesas tributárias e investimentos em mão-de-obra livre na América Latina. O caso de Cartagena das Índias (1750-1810)}

\section{Resumo}

No contexto dos recentes debates sobre a natureza da monarquia e do império espanhol, o Estado promotor militar e as características do gasto fiscal, este artigo apresenta algumas idéias sobre historiografia abordou algumas questões que de alguma forma abordam aspectos relacionados a investimentos nas colônias e à demanda de mão-de-obra pelas instituições da coroa. Eu quero ver, por um lado, até que ponto estes estudos modificar uma tradição historiográfica longa sobre as relações entre a coroa espanhola e suas possessões na América Latina, e, por outro lado, como o caso de Cartagena de Indias está localizado nesses debates e como pode ajudar a entender melhor, e no nível de uma localidade, algumas conseqüências sociais das reformas Bourbon.

Palavras-chave

Tesauro: Cartagena das Índias, reformas Bourbon, gastos fiscais, sistema de defesa, trabalhadores, investimentos, salários. 


\section{Presentación}

Mientras que las fortificaciones, el ejército y las milicias de Cartagena de Indias han sido objetos de estudios desde las perspectivas de la ingeniería militar, ${ }^{1}$ la composición social de las unidades militares, las consecuencias sociales y políticas del fuero militar entre los milicianos libres de color, ${ }^{2}$ y el financiamiento de las obras y de los sueldos del ejército, ${ }^{3}$ poco o nada conocemos sobre el mundo laboral vinculado a la construcción y el mantenimiento de baluartes, baterías y murallas, al Apostadero de la marina, a la real maestranza de la Artillería y a los talleres de armas de ejército y milicias. La falta de estudios sobre estos aspectos ha dejado su impronta en las investigaciones realizadas sobre los sectores subalternos de la ciudad, las que, al solo hacer referencias muy generales y vagas al mundo del trabajo en la ciudad, dejan un vacío en lo que se refiere al análisis de los procesos de movilidad y de diferenciación social, como también a los niveles de vida de las distintas franjas que formaban a la población trabajadora libre. Y aunque en recientes publicaciones me he esforzado en abordar distintos aspectos del mundo del trabajo vinculados a la defensa militar de Cartagena de Indias, ${ }^{4}$ el estudio del tema adquiere nuevas características cuando se les mira desde las perspectivas de los logros y debates de la reciente historiografía sobre el gasto fiscal en Hispanoamérica y la naturaleza de la monarquía española, en especial desde las inversiones en contratación de mano de obra que de alguna manera remiten al tema del impacto social de las reformas borbónicas en algunos espacios como eran las ciudades portuarias y plazas fuertes.

El artículo pretende crear un marco historiográfico de referencia y analizar las inversiones en contratación de mano de obra libre, para comprender de mejor forma las posibilidades laborales que existieron en Cartagena, los ingresos de los

\footnotetext{
${ }^{1}$ Juan M. Zapatero, Historia de las fortificaciones de Cartagena de Indias (Madrid: Centro Iberoamericano de Cooperación/Ministerio de Asuntos Exteriores, 1979); Enrique Marco Dorta, Cartagena de Indias. Puerto y plaza fuerte (Bogotá: Fondo Cultural Cafetero, 1988).

${ }^{2}$ Juan Marchena, La institución militar de Cartagena de Indias 1700-1810 (Sevilla: EEHA, 1982); Ejército y milicias en el mundo colonial americano (Madrid: Mapfre, 1992); Allan Kuethe, Reforma Militar y sociedad en la Nueva Granada, 1773-1808 (Bogotá: Banco de la República, 1993).

${ }^{3}$ Juan Marchena, "Capital, créditos e intereses comerciales a fines del periodo colonial: los costos del sistema defensivo americano. Cartagena de Indias y el sur del Caribe". Soldados del rey. El ejército borbónico en América colonial en vísperas de la independencia, eds. Allan Kuethe y Juan Marchena (Castelló de la Plana: Universitat Jaume I, 2005), 161-214; Adolfo Meisel Roca, "El situado de Cartagena de Indias a fines del Siglo de las Luces", El secreto del imperio español: los situados coloniales en el siglo XVIII, coords. Carlos Marichal y Johanna von Grafenstein (México: Colmex/Instituto Mora, 2012), 193211; José Serrano Álvarez, Fortificaciones y tropas. El gasto militar en Tierra Firme, 1700-1788 (Sevilla: CSIC, 2004); Ejército y fiscalidad en Cartagena de Indias. Auge y declive en la segunda mitad del siglo XVII (Bogotá: El Áncora Eds., 2006).

${ }^{4}$ Sergio Paolo Solano, "Sistema de defensa, artesanado y sociedad en el Nuevo Reino de Granada. El caso de Cartagena de Indias, 1750-1810”, Memorias, 10, 19, (2013): 92-139; “Artesanos, jornaleros y formas concentradas de trabajo: el Apostadero de la Marina de Cartagena de Indias (Nuevo Reino de Granada) en el tránsito entre los siglos XVIII y XIX", Theomai, 31, (2015): 79-105; "Pedro Romero, el artesano: trabajo, raza y diferenciación social en Cartagena de Indias a finales del dominio colonial", Historia Crítica, 61, (2016): 151-170; "Trabajadores, jornales, carestía y crisis política en Cartagena de Indias, 1750-1810", Historia, LI, 2, (2018): 549-488; "El costo social de la república: los trabajadores de los sistemas defensivos de Cartagena de Indias, 1750-1850, Historia y Memoria, 18, (2019): 243-287.
} 
trabajadores y el nivel de vida. Para ello he realizado una revisión de la historiografía que considero más significativa sobre esos temas y he consultado documentos del AGN de Colombia, del Archivo General de Simancas (España), Archivo General de la Marina “Álvaro Bazán” (España), que contienen información sobre inversiones en las defensas de Cartagena y en contratación de mano de obra. El diálogo entre la historiografía y la información de archivo, además de constatar las posibilidades brindadas por las nuevas perspectivas historiográficas, permite conocer los beneficios alcanzados por los trabajadores libres de la ciudad plaza-fuerte.

El artículo lo he organizado en tres partes: En la primera me refiero a una tradición historiográfica alimentada desde distintas vertientes ideológicas y políticas que acusan al dominio español del atraso que acusan las naciones hispanoamericanas, y también presento las reconsideraciones que se están realizando acerca de las políticas fiscales borbónicas, en especial a las inversiones de la corona en Hispanoamérica, lo que se viene denominando el gasto fiscal, para establecer un marco de referencia acerca de la demanda de trabajadores en las obras de defensa militar y públicas; en la segunda analizo el gasto fiscal en la Nueva Granada, con énfasis en las inversiones en la defensa militar de Cartagena de Indias a la luz de esas reconsideraciones historiográficas; y en la tercera analizo las inversiones en la contratación de mano de obra libre destinada a la construcción y el mantenimiento de las defensas.

\section{Debates sobre el gasto fiscal en Hispanoamérica y aportes de la historiografía fiscal reciente}

Una larga tradición política que luego se desdobló en historiográfica vincula la condición colonial y el atraso económico que acusan los países latinoamericanos con la naturaleza de las instituciones políticas, sociales y económicas que estableció la corona española en sus dominios, en especial con las restricciones impuestas en materia industrial y comercial, con las exacciones fiscales y extracción de capitales con destino a la metrópoli española y con la política guerrerista del imperio. Esta tradición se originó durante la formación de un imaginario sobre las identidades de las naciones latinoamericanas, subrayando lo que era visto como los aspectos negativos de los tres siglos de dominio español. ${ }^{5}$ A lo largo del siglo XX los debates iniciales sobre las peculiaridades de la esclavitud en las colonias inglesas y españolas, la propiedad territorial, las formas de control de la mano de obra, la cultura y la función de la iglesia, se retroalimentaron desde distintos puntos de vista disyuntivos que buscaban explicar el atraso latinoamericano. Feudalismo o capitalismo, gran hacienda y/o pequeña y mediana propiedad, mentalidad calvinista o mentalidad católica sobre los oficios y el bienestar económico, las relaciones desiguales entre centro y periferia, las implicaciones de la esclavitud solo negra -caso de los Estados Unidos- y de la esclavitud con mestizaje -caso de Iberoamérica-, sociedades de

\footnotetext{
${ }^{5}$ Tomás Pérez Vejo, "La difícil herencia: hispanofobia e hispanofilia en el proceso de construcción nacional mexicano", Los caminos de la ciudadanía. México y España en perspectiva comparada, eds. Manuel Suárez y Tomás Pérez Vejo (Madrid: Universidad de Cantabria, 2010), 219-230.
} 
hombres libres o sociedades de hombres sometidos a relaciones sociales serviles, formaron parte del acervo de tesis propuestas durante más de un siglo para explicar las diferencias entre los países del Hemisferio Norte y Latinoamérica.

En términos generales dos interpretaciones se han propuesto para explicar este atraso. Una acusa a la condición colonial por la creciente sustracción de recursos de las colonias para cubrir las necesidades de España en sus confrontaciones bélicas de la segunda mitad del siglo XVIII. ${ }^{6}$ La otra interpretación la debemos al economista e historiador estadounidense Douglass North, quien dio el toque más acabado a la idea del peso de las instituciones en el atraso latinoamericano. Interesado en las relaciones entre estas y el desarrollo económico a largo plazo, North argumentó que las diferencias entre la monarquía española e inglesa radicaron en que la primera creó instituciones para facilitar las extracciones fiscales de sus posesiones europeas y americanas, mientras que la corona inglesa nunca pudo montar en sus colonias grandes mecanismos de sustracción fiscal, y dedicó sus esfuerzos al crecimiento económico interno. Al depender su economía de lo que lograra sacar de sus colonias, la primera introdujo en aquellas instituciones de control que limitaron la libertad individual y los mecanismos de participación política, mientras que en el caso de la corona inglesa sucedió lo contrario. ${ }^{7}$

Stanley Engerman, Kenneth Sokoloff y Stephen Haber asumieron el desafío de llenar los vacíos del modelo de North, quien no explica los orígenes de esas instituciones y sus vínculos con los mundos hallados por los imperios europeos en las distintas áreas de América, y las diferencias entre las sociedades surgidas en América, pues consideraron que aquel modelo no era satisfactorio para explicar los profundos contrastes entre las colonias inglesas en América del Norte y las colonias inglesas del Caribe. Propusieron que un factor clave para entender los distintos niveles de desarrollo entre los países americanos es el de la dotación de factores naturales y humanos, los que establecieron las condiciones para determinar el tipo de instituciones que se introdujeron y desarrollaron en las distintas posesiones. Áreas de América con abundante población indígena y oro y plata; otras con baja densidad demográfica, pero con condiciones naturales favorables para el desarrollo de economías de plantación, lo que llevó a introducir la institución de la esclavitud en gran escala; y otras sin los anteriores elementos, pero con condiciones favorables para la agricultura de cereales, impulsaron el desarrollo de sociedades de pequeños y medianos agricultores. En

\footnotetext{
${ }^{6}$ Una de las obras más influyente de esta interpretación es la de Stanley Stein y Bárbara Stein, La herencia colonial de América Latina (México: Siglo XXI, 1980). Jacques Barbier y Herbert Klein, "Las prioridades de un rey ilustrado. El gasto público bajo el reinado de Carlos III", Revista de Historia Económica, 3, 3, (1985): 473-496. Puntos de vista críticos en Andrés Calderón y Rafael Dobado, "Siete mitos acerca de la historia económica del mundo hispánico", Pintura de los reinos. Identidades compartidas en el mundo hispánico. Miradas varias, siglos XVI-XIX, coords. Rafael Dobado y Andrés Calderón (Barcelona: Real Academia de la Historia/Fomento Cultural Banamex/Academia Mexicana de la Historia, 2012), 75-103; Andrés Calderón, Mirando a Nueva España en otros espejos. Cuatros ensayos sobre demografia y niveles de vida, siglos XVI-XIX (Madrid: tesis doctoral Universidad Complutense de Madrid, 2016).

7 Douglass North, Instituciones, cambio institucional y comportamiento económico (México: FCE, 1995); Douglass North, William Summerhill y Barry Weingast, “Orden, desorden y cambio económico: Latinoamérica vs. Norte América”, Instituciones y Desarrollo, 12-13, (2002): 9-59.
} 
las dos primeras se operó una concentración de las riquezas, originándose grandes desigualdades sociales, mientras que en las terceras se generaron sociedades más homogéneas. A lo largo del tiempo los efectos de esas relaciones entre disponibilidad de recursos e instituciones, fue que en las dos primeras las instituciones se encargaron de perpetuar grandes desigualdades sociales. ${ }^{8}$

Según Rafael Torres tres problemas historiográficos devienen del empleo de esos modelos: 1) Al dar prioridad al estudio de los ingresos y de los sectores sociales sobre los que recaían los impuestos, solo se concibe la relación entre el Estado y sociedad al nivel de las exacciones fiscales; 2) solo se ve en el gasto una especie de autofagia por parte del funcionamiento de instituciones improductivas (militares, burocracia e iglesia). Y las inversiones en la defensa militar solo se conciben como una anómala política económica y fiscal por parte de la corona española; y 3) no se tiene en cuenta que el análisis del gasto debe realizarse de acuerdo a la naturaleza del imperio español, y de los imperios de ese entonces que dedicaban la mayor parte de sus presupuestos a lo militar. ${ }^{9}$ Los anacronismos son evidentes al olvidar que no se trataba de un Estado de bienestar moderno que dirige sus inversiones a mejorías sociales, y los habitantes de las colonias no estaban enfrascados en una lucha por la formación de una nación independiente, y que concibieran los impuestos como algo ilógico, asignado por una nación externa y enemiga.

De igual forma, los estudios sobre la fiscalidad han señalado que para analizar el mundo hispanoamericano, en especial el siglo XVIII, es imprescindible tener presente que lo militar era un elemento constitutivo de las relaciones económicas, sociales y políticas cotidianas de las ciudades vinculadas a la defensa del imperio de sus enemigos exteriores en internos en los territorios de fronteras. ${ }^{10}$ Algunos estudiosos han incluido al imperio español en la categoría de "Estado fiscal militar" acuñada por John Brewer para analizar la combinación entre políticas imperiales, guerras, presiones fiscales y destino militar de una vasta proporción de los recaudos de la Inglaterra de finales del siglo XVII y durante casi todo el XVIII, y que invertir en la guerra no llevaba automáticamente por el camino del atraso económico. ${ }^{11}$

\footnotetext{
8 Stanley Engerman, Kenneth Sokoloff and Stephen Haber, "Factor Endowments and institutions", Economic development in the Americas since 1500. Endowments and institutions, Stanley E. Engerman and Kenneth L. Sokoloff (New York: Cambridge University Press, 2012), 31-93; Kenneth Sokoloff and Eric Zolt, "Inequality and the evolution of taxation", Economic development in the Americas since 1500, 168-211.

${ }^{9}$ Rafael Torres, "Las prioridades de un monarca ilustrado o las limitaciones del estado fiscal-militar de Carlos III", Hispania, LXVIII, 229, (2009): 407-436; El precio de la guerra. El Estado fiscal militar de Carlos III (1779-1783 (Madrid: Marcial Pons, 2013); "El gasto público en la España del siglo XVIII”, El gasto público en los imperios ibéricos, siglo XVIII, coord. Ernest Sánchez Santiró (México: Instituto Mora/ Conacyt, 2015), 23-72.

${ }^{10} \mathrm{~J}$. Serrano Álvarez, Ejército y fiscalidad en Cartagena de Indias.

${ }^{11}$ John Brewer, The sinews of power: war, money and the English State, 1688-1783 (Londres: Unwin, 1989); R. Torres, El precio de la guerra; "El gasto público en la España del siglo XVIII", 23-72. Esta última interpretación se ha visto reforzada gracias a que se ha reclamado la necesidad de insertar el estudio de España en una dimensión atlántica y a evitar la inveterada costumbre intelectual de ver la relación de
} 
En torno a la triada formada por las contribuciones fiscales extraídas a la población, los dispositivos administrativos para logarlos y los destinos que se daban a esos recursos (remesas a España y gasto fiscal en las colonias) se ha construido un nuevo escenario historiográfico, el que de manera sucinta se ha llamado la relación costos y beneficios de la condición colonial, tema que, según Carlos Marichal, debe estar en la base de cualquier consideración acerca de las consecuencias a largo plazo de la dominación española. ${ }^{12}$ Las investigaciones se han concentrado en tres frentes. El más avanzado está dedicado a las finanzas virreinales y de las distintas cajas reales provinciales y sufragáneas. Un segundo frente de estudios, menos desarrollado que el anterior, empieza a ver las reformas fiscales borbónicas en los espacios locales de ciudades y villas, estudiando los conflictos que suscitaron con las políticas impositivas de los cabildos. Y el tercer aspecto es el de los situados destinados al mantenimiento de las plazas fuertes costeras y de los presidios en las fronteras interiores de los virreinatos.

Otra variable que también ha permitido dar un renovado impulso a los estudios de las inversiones de las rentas establece las debidas diferencias entre las características de la monarquía española y las del Estado moderno. Durante mucho tiempo los estudios asimilaban la primera al segundo, caracterizándola como expresión del triunfo del Estado absolutista que centralizaba todo en desmedro de los intereses particulares y locales. Ahora sabemos que esa monarquía era una entidad política compuesta por múltiples jurisdicciones, de fueros públicos y privados sincronizados, pero que también colisionaban en muchas ocasiones, obligando al monarca a cumplir la función de árbitro, impartiendo, a la usanza del Antiguo Régimen, justicia y velando por la defensa de sus vasallos. ${ }^{13} \mathrm{~A}$ las instituciones que representaban diversas jurisdicciones ahora se les entiende como expresión de diversos intereses sociales y políticos que intervenían al momento de aplicar las reformas borbónicas, a las que muchas veces pudieron direccionar en beneficio propio. ${ }^{14}$

aquella con sus colonias solo en su beneficio. John Elliot, Imperios del Mundo Atlántico. España y Gran Bretaña en América, 1492-1830 (Madrid: Taurus, 2006).

${ }^{12}$ Carlos Marichal, "Beneficios y costos fiscales del colonialismo: las remesas americanas a España, 17601814", Finanzas y política en el mundo iberoamericano. Del Antiguo Régimen a las naciones independientes 1754-1850, coords. Ernest Sánchez Santiró, Luis Jaúregui y Antonio Ibarra (México: UNAM/Instituto Mora/Universidad del Estado de Morelos, 2001), 29-61; La bancarrota del virreinato. Nueva España y las finanzas del imperio español, 1780-1810 (México: FCE/Colmex, 1999), 31-62

${ }^{13}$ Bartolomé Yun, "Introducción. Entre el imperio colonial y la monarquía compuesta. Élites y territorios en la Monarquía Hispánica (ss. XVI y XVII)", Las redes del imperio. Élites sociales en la articulación de la monarquía hispánica, 1492-1714, dir. Bartolomé Yun (Madrid: Marcial Pons/Universidad Pablo de Olavide, 2009), 11-35. Un análisis sintético sobre el proceso constitutivo de la monarquía compuesta española en: Alejandra Irigoin y Regina Grafe, “Absolutismo negociado: la trayectoria hispánica en la formación del Estado y el imperio", El secreto del imperio español: los situados coloniales en el siglo XVIII, coords. Carlos Marichal y Johanna von Grafenstein (México: Colmex/Instituto Mora, 2012), 295-339.

${ }^{14}$ Antonio Hespanha, "Una nueva historia política e institucional”, Revista Mexicana de Ciencias Políticas y Sociales, 41, 166 (1996): 9-45; Carlos Garriga, "Orden jurídico y poder político en el Antiguo Régimen" Istor, 16, (2004): 13-44; "Os limites do reformismo bourbônico: a propósito da administração da justiça na América español”, Almanack, 6, (2013): 38-60; Jean Schaub, "Sobre el concepto de Estado", Historia Contemporánea, 28, (2004): 47-51. 
Esta manera de interpretar a la monarquía ha permitido a Ernest Sánchez Santiró distinguir dos elementos complementarios en el empleo de las finanzas reales. ${ }^{15}$ Una parte se destinaba a las arcas reales debido a la condición de Estado patrimonial de la corona. Pero a su vez, esa condición patrimonial y las necesidades de la res publica, generaba una tensión debido a que en la base de las relaciones entre el rey y sus súbditos estaba un criterio de justicia real que obligaba a la corona a velar por el bien y el cuidado de estos. ${ }^{16}$ Por eso, la corona delegaba en sus funcionarios subalternos la posibilidad de decidir inversiones en varios frentes, siendo los principales en la defensa militar de las posesiones y en obras públicas, concebidos tanto como una necesidad del imperio y como una necesidad de los vasallos y de sus intereses. Con base en estos supuestos Sánchez Santiró ha avanzado en el análisis de las inversiones de los recaudos en las colonias, aspecto que poco se conocía debido a que se daba por descontado y de forma a priori que en un contexto de continuas guerras las exacciones fiscales solo tomaban rumbo a las arcas reales para sostener el aparato militar. Ahora se comparan las proporciones entre las remesas que iban a España y lo invertido en las colonias, y para esto último se empieza a estudiar otras destinaciones, las que complejizan de mejor forma el panorama.

Asimismo, se empieza para tener en cuenta que las distintas jurisdicciones institucionales asumían iniciativas en materia de inversiones, ${ }^{17}$ diferenciándose entre las efectuadas por las corporaciones como los ayuntamientos que administraban los recursos municipales (propios y arbitrios), ${ }^{18}$ las llevadas a cabo por corporaciones que combinaban la condición privada/pública (iglesia, universidades, gremios, consulados), ${ }^{19}$ y las realizadas por las cajas reales principales. Cada una de estas esferas tenía su propia dinámica e intereses, y muchas veces podían coincidir en sus propósitos, y en otras ocasiones podían entran en conflictos. Pero también la corona tenía un discreto criterio jurisdiccional sobre cada una, y las podía intervenir bajo el principio de las prioridades de las inversiones. Colocar las inversiones y los recaudos

\footnotetext{
${ }^{15}$ Ernest Sánchez Santiró, "El gasto público de la Real Hacienda de Nueva España durante el siglo XVIII: estructura, dinámica y contradicciones”, El gasto público en los imperios ibéricos, siglo XVIII, 36-62

${ }^{16}$ Ernest Sánchez Santiró, "Introducción”, en El gasto público en los imperios ibéricos, 10-11.

${ }^{17}$ Ver esta distinción en Carlos Contreras, "El gasto público en el virreinato del Perú, 1700-1820”, E. Sánchez Santiró, El gasto público en los imperios ibéricos, 168-169.

18 Jorge Silva, La reforma fiscal de los ayuntamientos novohispanos (1765-1812) (Madrid: Universidad Michoacana/Universidad de Alcalá/Marcial Pons, 2015), 31-41; Esteban Sánchez de Tagle, "El monarca español y el gobierno de sus ciudades. La hacienda de la Ciudad de México", Formas de gobierno en México. Poder político y actores sociales a través del tiempo, vol. I, coord. Víctor Gayol (Zamora: Colmich, 2012), 173-187; "Las reformas del siglo XVIII al gobierno; la ciudad, su hacienda, su policía, su ejército", en C. García, Las reformas borbónicas, 1750-1808, 64-224; Yovana Celaya, "Impuestos locales en nueva España: negociación y obra pública en el ayuntamiento de Veracruz en el siglo XVIII”, Espacio, Tiempo y Forma, 27, (2014): 37-59

${ }^{19}$ Josefina Muriel, Hospitales de la Nueva España. Tomo II. Fundaciones de los siglos XVII y XVIII (México: UNAM/Cruz Roja, 1991); Marta García, "Impacto de las fundaciones piadosas en la sociedad queretana (siglo XVIII)", Cofradías, capellanías y obras pías en la América colonial, coords. María Martínez, Gisela von Wobeser y Juan Muñoz (México: UNAM, 1998), 247-262; Rosalva Loreto, "La caridad y sus personajes: las obras pías de don Diego Sánchez Peláez y doña Isabel de Herrera Peregrina. Puebla, siglo XVIII", M. Martínez, G. von Wobeser y J. Muñoz, Cofradías, capellanías y obras pías en la América colonial, 263-280.
} 
en estos distintos planos facilita el análisis de los objetivos centralizadores de las reformas fiscales ensayadas por los borbones a lo largo del siglo XVIII, y los distintos tratamientos que dieron a cada una de esas esferas.

Esta idea de la naturaleza compuesta de la monarquía española, y de la diversidad de jurisdicciones para decidir en materia de recaudos e inversiones, y de los consiguientes conflictos de potestades, también constituye el soporte de la reciente investigación de Esteban Sánchez de Tagle sobre los conflictos entre las autoridades centrales novohispanas y el cabildo de Ciudad de México a propósitos de las obras públicas de finales del siglo XVIII, lo que también ilustra el tema de los destinos de los dineros recaudados. ${ }^{20}$ Se trataba de disputas en torno a quienes tenían potestades para establecer contribuciones, echar manos de los dineros de las cajas reales que tenían estipulados otros destinos y realizar empréstitos con particulares, todo con el fin de financiar las obras públicas (empedrados de calles, alameda) emprendidas durante ese siglo. ${ }^{21}$ En esta dirección también ha trabajado Yovana Celaya a propósito de las inversiones realizadas por el ayuntamiento de la ciudad de Veracruz en algunas obras públicas, y sus conflictos con la administración de hacienda central novohipana. ${ }^{22}$

Otro tanto ha hecho Enriqueta Quiroz en su estudio sobre el financiamiento de algunas obras públicas en Ciudad de México durante los siglos XVII y XVIII (acueductos desde Santa Fe y Chapultepec, desagües y canalizaciones, calzadas, empedrados, iglesias, alamedas, palacio virreinal destruido por el motín del Parián de 1692, Casa de La Moneda y otros edificios públicos). Sugiere que el carácter orgánico de la monarquía implicaba una acción sincronizada entre las diferentes esferas del poder que llevaba a realizar el principio del bien común. El cabildo no solo garantizaba el orden (abasto, sanidad, precios, mejorías materiales), sino que sus inversiones en obras públicas, al igual que los gastos de la monarquía en esta materia, también debía garantizar la ocupación de la población como expresión de un principio del buen orden de la república. Luego del motín del Parián de 1692, se pronunció la preocupación por la ocupación de la población y se empezaron a aplicar medidas económicas utilitaristas por parte de la corona y de las autoridades novohispana para ofrecer fuentes de trabajo y así garantizar el orden social. ${ }^{23}$

En términos generales, los historiadores coinciden en anotar que durante la segunda mitad del siglo XVIII los dineros recaudados por las cajas reales tuvieron tres destinaciones, distinguiéndose entre las remesas que se enviaban a España; ${ }^{24}$ lo que

\footnotetext{
${ }^{20}$ Esteban Sánchez de Tagle, Del gobierno y su tutela. La reforma a las haciendas locales del siglo XVIII y el cabildo de México (México: INAH, 2014), 28-35.

${ }^{21}$ Esteban Sánchez de Tagle, Los dueños de la calle; Del gobierno y su tutela.

${ }^{22}$ Yovana Celaya, "Impuestos locales en nueva España", 37-59.

${ }^{23}$ Enriqueta Quiroz, Economía, obras públicas y trabajadores urbanos Ciudad de México: 1687-1907 (México: Instituto Mora, 2016), 46-48. Para el caso del virreinato del Perú Carlos Contreras ha mostrado que en un contexto de rebeliones antifiscales, la corona intentó una política de inversiones orientada por la racionalidad de evitar algunos factores del descontento social. C. Contreras, "El gasto público en el virreinato del Perú, 1700-1820”, 167-204.

${ }^{24}$ Carlos Marichal, "Beneficios y costos fiscales del colonialismo", 29-61.
} 
se invertía en las posesiones de ultramar, es decir, lo que se viene denominando los costos fiscales del colonialismo, incluyendo en esta parte los gastos administrativos, inversiones en obras y los gastos militares y los situados destinados a la defensa militar; 25 y los rubros aplicados al pago de deudas que la corona delegaba en sus colonias para así paliar el déficit fiscal, obligando a las autoridades centrales de los virreinatos a asumir políticas de endeudamientos privados. ${ }^{26}$

El conocimiento logrado sobre el funcionamiento de los recaudos fiscales y de las cajas reales, como también del situado destinado a la defensa militar, permiten tener una visión más equilibrada sobre lo enviado a España y lo invertido en las colonias. Aunque la corona se reservó el acopio de los recaudos de ciertos impuestos, la totalidad de los dineros que se mandaban a Madrid no obedecía a una cuota previamente establecida, ni tampoco eran centralizados por un organismo de las altas esferas virreinales. La historiografía reciente muestra dos hechos para tener en cuenta sobre este aspecto. Uno era que no siempre se cumplía las normas reales que establecían las destinaciones de lo recaudado. Así como la corona en principio se abrogó a su favor la destinación de ciertos impuestos, se sabe que los cabildos de ciudades y villas establecieron los suyos para poder sufragar los gastos en sus localidades. También se conoce que los excedentes de las distintas cajas principales y sufragáneas debían enviarse a las cajas centrales de los virreinatos, para que allí se decidiera que hacer con esos dineros. ${ }^{27}$ Sin embargo, entre el siglo XVI y comienzos del XVIII muchas decisiones las tomaban los funcionarios de las distintas cajas reales una vez se cubrían los gastos más indispensables de las localidades. Parte de los excedentes que se transferían desde las cajas subalternas a las cajas principales y de estas a las cajas reales de las principales ciudades portuarias para que tomasen

\footnotetext{
${ }^{25}$ Ángelo Alves y Ernest Sánchez Santiró, Guerra y fiscalidad en la Iberoamérica colonial (siglos XVII$X I X)$; C. Marichal y J. Grafenstein, El secreto del imperio español; Rafal Reichert, "Entre la paz y la guerra, el gasto militar novohispano en la región del Gran Caribe (1609-1648)", A. Alves y E. Sánchez Santiró, Guerra y fiscalidad en la Iberoamérica colonial, 39-64; Johanna von Grafenstein, "Situado y gasto fiscal: la real caja de México y las remesas para gastos militares en el Caribe, 1756-1783", A. Alves y E. Sánchez Santiró, Guerra y fiscalidad en la Iberoamérica colonial, 115-142. Sobre las inversiones en el virreinato del Perú ver Ramiro Flores, "Fiscalidad y gastos de gobierno en el Perú Borbónico", Compendio de historia económica del Perú. Tomo 3. Economía del periodo colonial tardío, ed. Carlos Contreras (Lima: Banco Central de la Reserva del Perú/IEP, 2010), 295-380. Sobre el virreinato del Río de la Plata, que en materia de situado dependía de las cajas del Perú, ver los balances historiográficos de Antonio Galarza, "La fiscalidad en el Río de la Plata tardocolonial: un posible balance historiográfico a partir de las cajas reales", Bibliographica Americana, 11, (2015): 9-30; Nicolás Biangardi, "Producción rural y fiscalidad en el Río de la Plata durante el siglo XVIII”. Bibliographica Americana, 11, (2015): 52-68.

${ }^{26}$ Estudio sobre el tema a finales de la colonia en: Carlos Marichal, "La iglesia y la crisis financiera del virreinato, 1780-1808: apuntes sobre un tema viejo y nuevo", Hacienda y política: las finanzas públicas y los grupos de poder en la primera República Federal mexicana, eds. José Serrano y Luis Jáuregui (Zamora: Colmich/ Instituto Mora, 1998), 97-161; Guillermina del Valle, "Respaldo financiero de Nueva España para la guerra contra la Gran Bretaña, 1779-1783”, A. Alves y E. Sánchez Santiró, Guerra y fiscalidad en la Iberoamérica colonial, 143-166. De esta autora ver el análisis de los prestamos forzados a través de la expropiación con posterior indemnización de bienes inmuebles y capitales de las obras piadosas mediante la extensión a las colonias de la Ley de Consolidación de Vales Reales en Finanzas piadosas y redes de negocios. Los mercaderes de la Ciudad de México ante la crisis de Nueva España, 1804-1808 (México: Instituto Mora, 2012).

${ }^{27}$ Herbert Klein, "Fiscalidad real y gastos de gobierno", Documento de trabajo 66, Serie Economía, 12, (1994): 9.
} 
rumbo a España, muchas veces podían tomar otras destinaciones, de acuerdo con las necesidades administrativas, eclesiásticas y militares locales y provinciales, y luego el remanente podía tomar rumbo a la metrópoli.

De igual forma se ha establecido que no todos los virreinatos enviaron de manera puntual, y año tras año, remesas a España. Algunos, como Nueva España, cargó con los mayores envíos, en especial durante la segunda mitad del XVIII y el primer decenio del XIX, mientras que otros, como Perú vio disminuir sus cuotas, y la Nueva Granada mandó menores cantidades. Sobre las transferencias a las arcas de la metrópoli para el periodo comprendido entre 1720 y 1799 y comparándola con los ingresos fiscales de las cajas centrales de Madrid, Carlos Marichal ha señalado que existió un continuo incremento de las remesas americanas, al pasar de representar en los ingresos totales de aquellas cajas el $15 \%$ entre 1765 y 1785 , al $25 \%$ en el decenio de 1790 , entre el $35 \%$ y el $40 \%$ durante los años de 1802-1804, y aproximadamente el 50\% en los años críticos de 1808-1811. En esos años los aportes de Nueva España fueron superiores al resto de los virreinatos, representando el 50\% entre 1773-1787, y entre 1788-1810 constituyó el 75\% de los totales de las remesas provenientes de las colonias. ${ }^{28}$ Las compilaciones estadísticas elaboradas por John Tepaske y Herbert Klein también dan a conocer lo que sucedía con los dineros recaudados por las cajas reales de Lima. Cuando observamos los ingresos y gastos de las cajas de esa ciudad se concluye que buena parte de los dineros recaudados se invertía en el funcionamiento de la administración, en el sector militar y en los situados destinados a Panamá, Valdivia y Chiloé. Las remesas a Castilla se aproximaron a los 5.000 .000 pesos, las sumas destinadas a los situados rayaron en los 22.000 .000 pesos, y lo invertido en gastos militares estuvo un poco por encima de los 54.000 .000 pesos. $^{29}$

Las series elaboradas por Carlos Marichal y Matilde Souto sobre las remesas de Nueva España a la península y los situados destinados a las plazas fuertes del Caribe les permiten concluir que entre 1720 y 1800 la real hacienda del virreinato de Nueva España sostuvo la defensa militar del Gran Caribe, por vía de los situados que enviaba a La Habana, Puerto Rico, Santo Domingo, San Agustín de la Florida, como también a las Filipinas, y que los gastos en situados fueron mucho mayores en comparación con las remesas remitidas a la metrópoli española. Entre 1720 y 1799 los situados enviados al Caribe duplicaron las remesas remitidas a Madrid, siendo el promedio anual de los primeros 271.063 pesos, y 143.239 pesos el de las remesas. ${ }^{30}$ En fecha reciente Rafal Reichert al estudiar el situado destinado para el mantenimiento de las defensas militares de ciudades insulares y del canal de la Florida en el mar Caribe, y su relación con el gasto de las cajas reales de Nueva España durante el siglo XVII, ha

\footnotetext{
${ }^{28}$ Carlos Marichal, La bancarrota del virreinato, 36, 303-305; Carlos Marichal y Matilde Souto, "La Nueva España y los financiamientos del imperio español en América: los situados para el Caribe en el siglo XVIII", C. Marichal y J. Grafenstein, El Secreto del imperio español, 92-93.

${ }^{29}$ Cajas de la Real Hacienda de la América Española, siglos XVI a principios del siglo XIX. http:// realhacienda.colmex.mx/; Ramiro Flores, "Los situados peruanos: desde Chile hasta Panamá (1700-1800)", en C. Marichal y J. Grafenstein, El secreto del imperio español, 33-59.

${ }^{30}$ Carlos Marichal y Matilde Souto, "La Nueva España y los financiamientos del imperio español en América", 91-93.
} 
indicado que el primero correspondió al 32,5\% de las remesas a la metrópoli y casi al $10 \%$ del gasto total de las cajas reales de ese virreinato. Pero si se analiza esa relación de acuerdo con ciertos ciclos de guerras y del estado de las finanzas de Madrid, las proporciones varían de forma significativa, mostrando, por ejemplo, que durante el último decenio de ese siglo el situado invertido en gasto militar representó casi el 91\% del valor total de las remesas enviadas a España. ${ }^{31}$

Y al comparar los ingresos de las cajas reales de Buenos Aires con las partidas del situado del siglo XVIII, Martín Cuesta ha anotado que este representaba el más importante rubro de aquellas a partir del decenio de $1760 .{ }^{32}$ Para el virreinato de La Plata, Tulio Halperin Donghi señaló que entre 1791 y 1810, la suma destinada al situado por las cajas reales de Buenos Aires siempre estuvieron por encima de las remesas enviadas a España. ${ }^{33}$ Según Lyman Johnson desde la organización de la expedición militar de Cevallos, la creación del virreinato de La Plata (1776), las guerras con los portugueses y luego con los intentos de invasión inglesa, la principal fuente de trabajo de artesanos y jornaleros de Buenos Aires fue en todo lo relacionado con la defensa militar y las obras públicas. ${ }^{34}$

\section{Gasto fiscal en la Nueva Granada: el caso de las defensas militares de Cartagena de Indias}

Las discusiones y avances de las historiografías sobre la naturaleza de la monarquía española, el Estado fiscal militar, las remesas a España y el gasto físcal han creado un marco propicio para interpretar de mejor forma el caso de Cartagena de Indias y del Nuevo Reino de Granada en lo relacionado con los destinos de los dineros destinados al mantenimiento de la defensa militar y sus consecuencias sociales. Esta ciudad, principal puerto neogranadino y principal bastión de la defensa del Caribe sur hispánico, tuvo prerrogativas jurisdiccionales de las que carecían otras poblaciones, debido a sus funciones en los circuitos comerciales y en los sistemas militares defensivos del imperio español. El mantenimiento de esos sistemas (fortificaciones, artillería y el apostadero de marina con sus barcos de guerra y guardacostas y de los batallones de soldados, marinería y milicias) obligaba a que las demás ciudades y villas enviaran a Cartagena parte de los ingresos de sus cajas reales a través de una figura fiscal que se llamó el situado. Pero como este no daba abasto para cubrir las necesidades de las defensas, o porque llegaba atrasado, las cajas reales de la ciudad suplían los faltantes y atrasos, otorgaban adelantos, y avalaban empréstitos solicitados a los comerciantes. ${ }^{35}$

\footnotetext{
${ }^{31}$ Rafal Reichert, "El situado novohispano para la manutención de los presidios españoles en la región del golfo de México y el Caribe durante el siglo XVII", Estudios de Historia Novohispana, 46, (2012): 47-81.

${ }^{32}$ Martín Cuesta, "Impuestos imperiales: la caja real de Buenos Aires (1700-1800)", Temas de Historia Argentina y Americana, 14, (2009): 45-48.

${ }_{33}$ Tulio Halperin Donghi, Guerra y finanzas en los orígenes del Estado argentino 1791-1850 (Buenos Aires: Prometeo, 2005), 62-66, 119.

${ }^{34}$ Lyman Johnson, Los talleres de la revolución. La Buenos Aires plebeya y el mundo del Atlántico, 17761810 (Buenos Aires: Ed. Prometeo, 2013), 287-301.

${ }^{35}$ Los argumentos de Adolfo Meisel y José Serrano Álvarez sobre la economía de Cartagena y los orígenes
} 
Situados y aportes de las cajas reales se complementaban y se irradiaban entre distintos sectores de la sociedad, dinamizando la economía local y la de las áreas circunvecinas, por medio de compra y transporte de materiales, adquisición de provisiones, contratación de mano de obra, contratos con asentistas, sueldos de soldados, alquileres de locales, este privilegio fiscal se distribuía de forma asimétrica entre diversos sectores de la población de esta ciudad y en sus áreas circunvecinas. ${ }^{36}$ Además, con las necesidades de las defensas surgieron unas relaciones entre los trabajadores y las instituciones políticas y militares coloniales que estuvieron más allá de las circunscritas a los gremios, las que les permitieron sacar cierta ventaja frente a la jurisdicción de la justicia ordinaria, en la medida en que los puertos eran sociedades militarizadas y escenarios de conflictos entre los poderes ordinarios y militares. ${ }^{37}$

Para entender de mejor manera estas afirmaciones lo primero es dejar a un lado la idea de un absoluto sangrado fiscal de los recursos de la Nueva Granada que salían con destino a España por vía de remesas. Como señaló hace algunos años Hermes Tovar Pinzón, la paradoja de las posesiones hispanoamericanas fue que las continuas guerras interimperiales obligaron a la corona a invertir en sus posesiones americanas, lo que redujo de forma significativa el monto de las remesas enviadas a la península Ibérica. ${ }^{38}$ Óscar Rodríguez y Decsi Arévalo analizaron las remesas neogranadinas ${ }^{39}$

de las inversiones en su defensa militar están en contravía. Según A. Meisel era el situado el principal elemento dinamizador de la economía local. Adolfo Meisel Roca, “Situado o contrabando? Las bases económicas de Cartagena de Indias a fines del Siglo de las Luces", El Golfo-Caribe y sus puertos. Tomo I, 1600-1850, coord. Johanna von Grafenstein (México: Instituto Mora, 2006), 43-90. José Serrano Álvarez anota que la mayoría de los recursos provenían de los recaudos de las cajas reales de la ciudad, lo que nos coloca ante la afirmación de una economía dinámica. José Serrano Álvarez, "Apuntes para una metodología del estudio del gasto militar en Indias", Temas Americanistas, 15, (2002): 75-89; "Situados y rentas en Cartagena de Indias durante el siglo XVIII", Temas Americanistas, 17, (2004): 58-78; "Economía, rentas y situados en Cartagena de Indias, 1761-1800", Anuario de Estudios Americanos, 63, 2, (2006): 75-96.

${ }^{36}$ Arturo Betancur, "La provisión de servicios en el puerto colonial de Montevideo: Alcances y limitaciones de una fuente local de riqueza". Anuario de Estudios Americanos, LIII, 2, (1996): 123-145; Germán Andrade, Un mar de intereses, la producción de pertrechos navales en Nueva España, siglo XVIII (México: Instituto Mora, 2006); Emilio Luque, Arquitectura y mano de obra en el Uruguay colonial: sobrestantes, herreros, carpinteros, albañiles y picapedreros (Zaragoza: Pórticos Librerías, 2010); Fernando Jumar et al, "El comercio ultramarino y la economía local en el complejo portuario rioplatense, siglo XVIII". Anuario del IEHS, 21, (2006): 235-254; María Sandrín, La demanda de bienes y servicios para la Corona y la navegación ultramarina en el complejo portuario rioplatense y la dinamización de la economía regional 1680-1810, 2 vols. (La Plata: tesis doctoral Universidad Nacional de La Plata, 2016).

${ }^{37}$ Sergio Paolo Solano, "El costo social de la república", 243-287.

${ }^{38}$ Hermes Tovar, El imperio y sus colonias: las cajas reales de la Nueva Granada en el siglo XVI (Bogotá: AGN, 1999), 79-102; "Remesas, situados y real hacienda en el siglo XVII", 241-268. Otros estudios sobre este virreinato: Juan Marchena, "La financiación militar en Indias: introducción a su estudio", Anuario de Estudios Americanos, XXXVI, (1979): 81-110; "Capital, créditos e intereses comerciales a fines del periodo colonial", 161-214; Álvaro Jara, "El financiamiento de la defensa en Cartagena de Indias: los excedentes de las cajas de Bogotá y de Quito, 1761-1802”, Historia, 28, (1994): 117-182; María Laviana, “Excedente fiscal y defensa del imperio: El ‘situado' de Guayaquil a Cartagena en el siglo XVIII”, Revista del CESLA, 11, (2008): 93-104; Decsi Arévalo y Oscar Rodríguez, "La fiscalidad bajo un régimen de dominación colonial: el caso de la caja real de Cartagena 1738-1802", Anuario Colombiano de Historia Social y de la Cultura, 35, (2008): 19-64; A. Meisel Roca, “Situado o contrabando?”, 43-90.

${ }^{39}$ Sobre las cajas reales neogranadinas se cuenta con alguna historiografia: Oscar Rodríguez, "La Caja Real de Popayán”, Anuario Colombiano de Historia Social y de la Cultura, 15, (1987): 5-36; H. Tovar, El imperio y sus 
enviadas a España desde Cartagena de Indias, En fechas más reciente Adolfo Meisel Roca estudió la función del situado destinado al mantenimiento de la defensa militar en la vida económica de Cartagena. ${ }^{40} \mathrm{Y}$ algo parecido ha hecho José Serrano Álvarez en sus estudios sobre los recursos invertidos en la defensa militar de Cartagena. ${ }^{41}$

Cuando cruzamos las cifras aportadas por estos historiadores las conclusiones toman parecida dirección a la que había señalado Hermes Tovar. El promedio anual de las remesas a España fue de 95.038 pesos, y el promedio del gasto militar en los puertos del Caribe neogranadino ascendió a 583.555 pesos, multiplicando casi 6 y 2,3 veces respectivamente a las remesas. El promedio de estas es sumamente bajo si se observa que entre 1720 y 1770 el promedio anual enviado desde Nueva España ascendió a la suma de 1.000 .000 pesos. $^{42}$

Pero han sido las investigaciones de José Serrano Álvarez las que nos han brindado las mejores condiciones para justipreciar las cantidades de dineros invertidas en las defensas de Cartagena entre la segunda mitad del siglo XVII y el año de 1788. Entre 1645 y 1699 se invirtió la suma de 1.983 .394 pesos en fortificaciones y en la marina. ${ }^{43}$ En los siguientes 50 años (1700-1749) las inversiones alcanzaron un total de 8.237.000 pesos. Y en los 39 años restantes (1750-1788) las erogaciones destinadas a la defensa llegaron al monto total de 21.097 .000 pesos, con un crecimiento del $129 \%$ con relación a los cien años precedentes. ${ }^{44}$

Las comparaciones de cifras entre lo enviado a la metrópoli y lo invertido en las colonias ha llevado a algunos historiadores a debatir sobre el impacto del gasto militar (incluyendo los situados) sobre las economías coloniales. Además, gracias a las recientes operaciones que desagregan los gastos fiscales empezamos a saber cómo se irradiaban en el tejido social los dineros destinados a la defensa militar. Una conclusión que se saca en limpio es la de que las transferencias inter-virreinales e interprovinciales a través del situado terminaba favoreciendo algunas ciudades y áreas

colonias, 79-102; "Remesas, situados y real hacienda en el siglo XVII", 241-268; D. Arévalo y O. Rodríguez, "La fiscalidad bajo un régimen de dominación colonial", 19-64; Adolfo Meisel Roca, "Los ingresos fiscales y la economía del virreinato de Nueva Granada, 1761-1800", en J. Gelman, E. Llopis y C. Marichal, Iberoamérica y España antes de la independencia, 265-305; Edwin Muñoz, "Estructura del gasto y del ingreso en la Caja Real de Santafé, 1803-1815", Anuario Colombiano de Historia Social y de la Cultura, 37, 2, (2010): 45-85; Carlos Díaz, "Hacienda pública en tiempos de guerra: la caja real de Santafé de Bogotá durante la reconquista de la Nueva Granada, 1816-1818”, Fronteras de la Historia, 18, 1, (2013): 129-164; José Pinto, Entre colonia y república. Fiscalidad en Ecuador, Colombia y Venezuela, 1780-1845 (Bogotá: tesis doctoral-Universidad Nacional, 2014); "Impacto fiscal de las reformas borbónicas y del proceso independentista en la caja real y tesorería provincial de Antioquia 1750-1819”, Revista Uruguaya de Historia Económica, VI, 10, (2016): 9-23; José Pinto y Carlos Díaz, "Fiscalidad en Popayán, 1750-1821”, Tiempo \& Economía, 3, 2, (2016): 33-54.

${ }^{40}$ Antonio Meisel Roca, “Situado o contrabando?”, 43-90.

${ }^{41}$ José Serrano Álvarez, "El factor humano en la defensa de Tierra Firme: sueldos en Cartagena de Indias 1700-1788", Temas Americanistas, 16, (2003): 64-80; "Economía, rentas y situados en Cartagena de Indias, 1761-1800", 75-96; Ejército y fiscalidad en Cartagena de Indias; Fortificaciones y tropas. El gasto militar en Tierra Firme, 1700-1788.

${ }^{42}$ Carlos Marichal y M. Souto, "La Nueva España y los financiamientos del imperio español en América”, 66.

${ }^{43}$ José Serrano Álvarez, Ejército y fiscalidad en Cartagena de Indias, 250-251, 266-267.

${ }^{44}$ José Serrano Álvarez, Fortificaciones y tropas, 357, 378-379. 
geográficas en detrimentos de otras. Emilio Duque, Florencia Thul, Fernando Jumar y María E. Sandrín han estudiado las relaciones entre las destinaciones presupuestales y la construcción y mantenimiento de los sistemas defensivos del área del Río de la Plata (fortificaciones de la ciudad de Montevideo, fundada en 1729, mantenimiento de barcos guardacostas y de correo, talleres de armas de ejércitos y artillería), con acento en los contratos de asentistas y en los gastos en mano de obra, las características de esta, los oficios, las calificaciones, los periodos laborales, los salarios devengados y los problemas presupuestales. ${ }^{45}$ José Serrano Álvarez ha analizado las inversiones del situado de La Habana en el astillero y en los contratos de asentistas, con referencias a los montos globales en mano de obra. ${ }^{46}$ Lo mismo han hecho Yovana Celaya, Germán Andrade, Johanna von Grafenstein y Guadalupe Pinzón para los puertos novohispanos. ${ }^{47}$ De nuestra parte hemos aportado al conocimiento de la mano de obra vinculada al Apostadero de la Marina de Cartagena de Indias. Aunque Lawrence Clayton y María Laviana no relacionan situados con gastos en el astillero de Guayaquil, si analizaron la contratación de mano de obra. ${ }^{48}$

Para el caso de Cartagena de Indias, el estudio de Adolfo Meisel Roca sobre el situado para el mantenimiento de las defensas de esa plaza fuerte ilustra que entre 1761 y 1800 estas llegaron a representar alrededor del 50\% de los ingresos fiscales de las Cajas Reales de las principales poblaciones del Caribe neogranadino. ${ }^{49}$ Utilizando otras fuentes de archivos José Serrano Álvarez demuestra que entre 1700

\footnotetext{
${ }^{45}$ Florencia Thul, "Relaciones laborales en el sector de la construcción en el Montevideo tardo-colonial. La construcción de las fortificaciones y de la iglesia matriz, 1760-1808", Revista Uruguaya de Historia Económica, VI, 10, (2016): 48-64; Emilio Luque, Ciudad y poder. La construcción material y simbólica del Montevideo colonial y sus imaginarios (1723-1810) (Sevilla: CSIC/Diputación de Sevilla, 2007); Arquitectura y mano de obra en el Uruguay colonial. Sobrestantes; Fernando Jumar y María E. Sandrín, "El gasto público como dinamizador de la economía local. Rio de la Plata, en la primera mitad del siglo XVIII", E. Sánchez Santiró, El gasto público, 205-272; M. E. Sandrín, La demanda de bienes y servicios para la Corona, tomo I, 20-182.

${ }^{46}$ José Serrano Álvarez, El astillero de La Habana en el siglo XVIII. Historia y construcción naval (17001805) (Madrid: Ministerio de Defensa, 2018); José Serrano Álvarez y Allan Kuethe, "El situado mexicano y la Cuba borbónica", C. Marichal y J. Grafenstein, El secreto del imperio español, 95-114.

${ }^{47}$ Yovana Celaya, Alcabalas y situados. Puebla en el sistema fiscal imperial 1638-1742 (México: Colmex/ Fideicomiso de Historia de las Américas, 2010), 111-123; Johanna von Grafenstein, "Políticas y prácticas de abasto de las plazas militares españolas en el Caribe", El Caribe: región, frontera y relaciones internacionales coords. Johanna von Grafenstein y Laura Muñoz (México: Instituto Mora, 2000), 257-314; "La provisión de las armadas y presidios de las islas de barlovento: intereses novohispanos versus habaneros (1760-1780)", en Guillermina del Valle (coord.), Mercaderes, comercio y consulados de Nueva España, 1663-1810 (México: Instituto Mora, 2003), 67-97; "Provisión de víveres para la real armada y presidios de Barlovento en el siglo XVIII: su arrendamiento a particulares o administración directa”, en M. Martínez, E. Sánchez Santiró y M. Souto, La fiscalidad novohipana en el imperio español, 105-138; G. Andrade, Un mar de intereses. La producción de pertrechos navales en Nueva España, siglo XVIII; Iván Valdez-Bubnov, Poder naval y modernización del Estado: política de construcción naval española (siglos XVI-XVIII) (México: UNAM/ Bonilla Artigas/Iberoamericana, 2011); Guadalupe Pinzón, Acciones y reacciones en los puertos del Mar del Sur. Desarrollo portuario del Pacífico novohispano a partir de sus politicas defensivas, 1713-1789 (México: UNAM/Instituto Mora, 2011); Hombres de mar en las costas novohispanas. Trabajos, trabajadores y vida portuaria en el departamento marítimo de San Blas (siglo XVIII) (México: UNAM, 2014).

${ }^{48}$ Lawrence Clayton, Los astilleros de Guayaquil colonial (Guayaquil: Casa de la Cultura Ecuatoriana Núcleo del Guayas, 1978); María Laviana, Guayaquil en el siglo XVIII. Recursos naturales y desarrollo económico (Sevilla: CSIC/EEHA, 1987), 227-301.

${ }^{49}$ Meisel Roca, 43-90.
} 
y 1736, el promedio anual de gastos militares de la ciudad fue de 102.000 pesos. Con los preparativos por el conflicto con Inglaterra (1739-1741), entre 1737 a 1772 ese promedio pasó a 279.000 pesos. Y con la reforma militar borbónica para los años de 1773 a 1788 subió a 607.000 pesos..$^{50}$

El incremento de las labores en los frentes de la defensa militar demandó inversiones por parte de la corona. Ese progresivo aumento de los gastos en las defensas de la ciudad no solo tuvo que ver con el aumento del pie de fuerza de los militares del Regimiento Fijo, sino que también se debió a las construcciones y refacciones de baluartes, fuertes, murallas, como también de embarcaciones y pertrechos de guerra. La investigación de José Serrano Álvarez sobre el gasto militar en el Caribe neogranadino durante casi todo el siglo XVIII permite tener una idea exacta sobre esas inversiones y sus destinaciones (ver tabla 1 y gráfico 1 ).

Esto marchó aparejado con cierta disminución del peso de la representación de los sueldos del ejército en el total del gasto militar de la ciudad, pues si entre 1725 y 1749 el porcentaje promedio anual de la representatividad de los sueldos en el total del gasto militar fue del 84,2\%, para los años comprendidos entre 1750 y 1774 ese porcentaje promedio disminuyó al 56\%. y entre 1775 y 1788 subió levemente al $61,2 \%$. Al crecer los promedios de presupuestos asignados a las fortificaciones y el Apostadero de la marina, esas variaciones se expresaron en el aumento de las asignaciones para contratación de mano de obra (ver tabla y gráfico 1).

Las cifras de las inversiones en el Arsenal-Apostadero de Cartagena ayudan a dar una idea sobre el incremento de los trabajos, y del número de trabajadores. Según la pormenorizada investigación de José Serrano sobre los gastos militares en Cartagena, Riohacha, Santa Marta, Portobelo y Panamá, los datos reunidos en los fondos de Contaduría, Santa Fe y Panamá del Archivo General de Indias (España) señalan que durante el siglo XVIII las inversiones en la armada de Cartagena se fueron incrementado en proporciones significativas. Entre 1700 y 1752 se invirtió un total de 67.000 pesos. Entre 1753 y 1772 la cifra se incrementó a 1.391 .000 pesos. Y entre 1773 y 1788 subió a 2.600 .000 pesos. Según las cifras aportadas por el citado historiador los años picos en las inversiones fueron de 1762 a 1764, y de 1781 a 1788, con cifras presupuestales de seis dígitos. ${ }^{51}$

$\mathrm{Y}$ otros datos que he encontrado en los fondos documentales Guerra y Marina, Miscelánea, Virreyes y Milicias y Marina del AGN de Colombia, indican que entre 1796 y 1799 se invirtió la suma de 1.396 .000 pesos, y entre 1806 y 1809 el gasto ascendió a 1.526 .000 pesos. ${ }^{52}$ Estos incrementos se debieron a los aportes de las Cajas Reales de la ciudad, lo que valga señalarlo de paso, causaba mucho malestar en la administración ordinaria de Cartagena. En 1793, en medio de los preparativos por

\footnotetext{
${ }^{50}$ Jóse, Serrano Álvarez, Fortificaciones y tropas, 286-287, 311, 320-321, 356-357, 378-379, 385-386.

${ }^{51}$ José, Serrano Álvarez, Fortificaciones y tropas, 286-287, 311, 320-321, 356-357, 378-379, 385-386.

${ }^{52}$ AGN, SAA I-16, GM, leg.62, carpeta 1, ff.402r., 465r.; leg.73, carpeta 6, ff.983r., 985r.; leg.74, carpeta 8, f.760v.; leg.78, carpeta 11, f.778r.; leg.78, carpeta 12, f.778r.; leg.78, carpeta 13, ff.783r.-825r.; leg.93, carpeta 12, ff.190r.-244v.; leg.102, carpeta 11, f.224r.; AGN, Virreyes, leg.6, doc.27, f.1232r.; AGN, SC, MM, leg.47, doc.30, f.447r.; AGN, SC, Miscelánea, leg.100, doc.38, f.631r.
} 
un posible conflicto armado entre Francia y España, el ingeniero militar Antonio de Arévalo, informaba que en el ramo de la Artillería las inversiones realizadas entre 1779 y 1791 ascendían a la suma de 333.414 pesos, incluyendo los gastos en sueldos de la oficialidad y de los artilleros, como también de las maestranzas de los trabajadores. ${ }^{53}$

Tabla 1. Inversiones en sistemas defensivos, Cartagena 1700-1788.

\begin{tabular}{|c|c|c|c|c|c|c|c|c|c|c|c|}
\hline \multirow[b]{2}{*}{ Quinquenios } & \multicolumn{8}{|c|}{ Gastos (miles de pesos) } & \multicolumn{3}{|c|}{$\%$} \\
\hline & 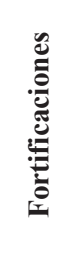 & & 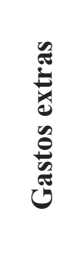 & 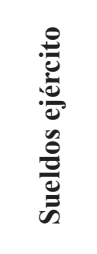 & 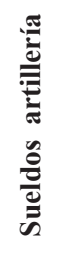 & 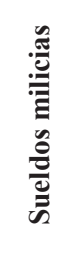 & 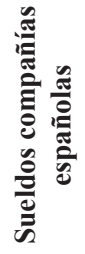 & 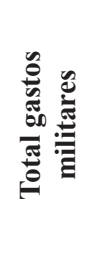 & 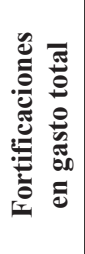 & 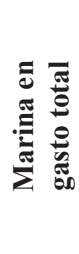 & 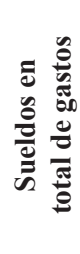 \\
\hline $1700-1704$ & 123 & 227 & 107 & 488 & & 17 & & 961 & 12,8 & 23,6 & 52,5 \\
\hline $1705-1709$ & 78 & 35 & 18 & 361 & & 13 & & 505 & 15,3 & 7,0 & 74,1 \\
\hline $1710-1714$ & 55 & 2 & 13 & 315 & & 10 & & 387 & 14,1 & 0,4 & 81,8 \\
\hline $1715-1719$ & 138 & 46 & 12 & 321 & & 11 & & 528 & 26,1 & 8,7 & 62,9 \\
\hline $1720-1724$ & 45 & 75 & 6 & 263 & & 0.3 & & 388 & 11,5 & 19,2 & 67,7 \\
\hline $1725-1729$ & 55 & 76 & 4 & 392 & & 25 & & 551 & 10,0 & 13,8 & 76,1 \\
\hline $1730-1734$ & 61 & 12 & 5 & 303 & & 0 & & 382 & 16,0 & 3,2 & 79,4 \\
\hline $1735-1739$ & 59 & 20 & 15 & 464 & & 0.7 & & 558 & 10,5 & 3,6 & 83,2 \\
\hline $1740-1744$ & 168 & 88 & 12 & 1.427 & & 299 & 455 & 2.448 & 6,9 & 3,6 & 89,1 \\
\hline $1745-1749$ & 103 & 3 & & 1.054 & & 0 & 359 & 1.519 & 6,8 & 0,2 & 93,2 \\
\hline $1750-1754$ & 174 & 114 & & 624 & & 0 & & 912 & 19,1 & 12,5 & 68,4 \\
\hline $1755-1759$ & 414 & 268 & & 699 & & 0 & & 1.381 & 30,0 & 19,4 & 50,6 \\
\hline $1760-1764$ & 402 & 426 & 8 & 870 & & 0 & 224 & 1.923 & 20,9 & 22,2 & 56,6 \\
\hline $1765-1769$ & 646 & 206 & 19 & 711 & & 0 & & 1.582 & 40,8 & 13,0 & 45,0 \\
\hline $1770-1774$ & 589 & 283 & 58 & 1.072 & 74 & 0 & 222 & 2.298 & 25,7 & 12,3 & 59,5 \\
\hline $1775-1779$ & 561 & 75 & 164 & 1.316 & 12 & 277 & & 2.522 & 22,2 & 3,0 & 68,3 \\
\hline $1780-1784$ & 498 & 341 & 878 & 2.224 & 166 & 689 & 403 & 5.198 & 9,6 & 6,6 & 67,0 \\
\hline $1785-1788$ & 351 & 696 & 1.713 & 1.659 & 126 & 194 & 545 & 5.281 & 6,6 & 13,2 & 47,8 \\
\hline Totales & 4.519 & 3.245 & 3.031 & 14.561 & 378 & 1.526 & 2.208 & 29.325 & & & \\
\hline
\end{tabular}

Fuente: José Serrano Álvarez, Fortificaciones y tropas, 286-287, 311, 320-321, 356-357, 378-379, 385 386. Si tomamos los conflictos interimperiales como hitos de la periodización de las inversiones, entre 1700 y 1739 (preparativos para resistir el asedio de la escuadra inglesa del almirante Edward Vernon) el promedio anual de los gastos militares en Cartagena fue de 109.226 pesos. Entre 1740 a 1764 (toma de La Habana por los ingleses y el inicio de la reforma militar borbónica) pasó a 327.295 pesos. Y entre 1765 y 1788 (marcado por la guerra contra Inglaterra de 1778-1783) se incrementó a 703.462 pesos. Al desagregar las cifras de gastos globales en lo que correspondió a cada sistema defensivo y en pago de sueldos a militares, el ejercicio de Serrano Álvarez señala que a partir de mediados del decenio de 1750 empezaron a crecer las inversiones en fortificaciones y en la marina, pasando los promedios en estos ramos de 18.552 y 8.289 pesos a 92.735 y 54.039 pesos respectivamente. Y en el mismo orden, entre 1775 y 1788 subieron a 100.714 y 79.443 pesos. ${ }^{54} \mathrm{Y}$ otros datos que he hallado en el AGN indican que entre 1796 y 1799 en el Apostadero se ejecutó la suma de 1.396 .000 pesos (promedio anual de 349.000 pesos), y entre 1806 y 1809 pasó a 1.526.000 pesos (promedio anual de 381.500 pesos).$^{55}$

${ }^{53}$ AGN, SC, MM, leg.72, doc.181, ff.875r.-880r

${ }^{54}$ José Serrano Álvarez, Fortificaciones y tropas, 148-149, 214-215.

${ }^{55}$ Archivo General de la Nación-Colombia (AGN), Sección Archivos Anexos (SAA) I-16, Guerra y Marina (GM), leg.62, carpeta 1, ff.402r., 465r.; leg.73, carpeta 6, ff.983r., 985r.; leg.74, carpeta 8, f.760v.; leg.78, 
Gasto fiscal e inversiones en mano de obra libre en Hispanoamérica. El caso de Cartagena...

Gráfico 1. Gasto militar por quinquenios y participación porcentual de sueldos de militares (1700-1788).

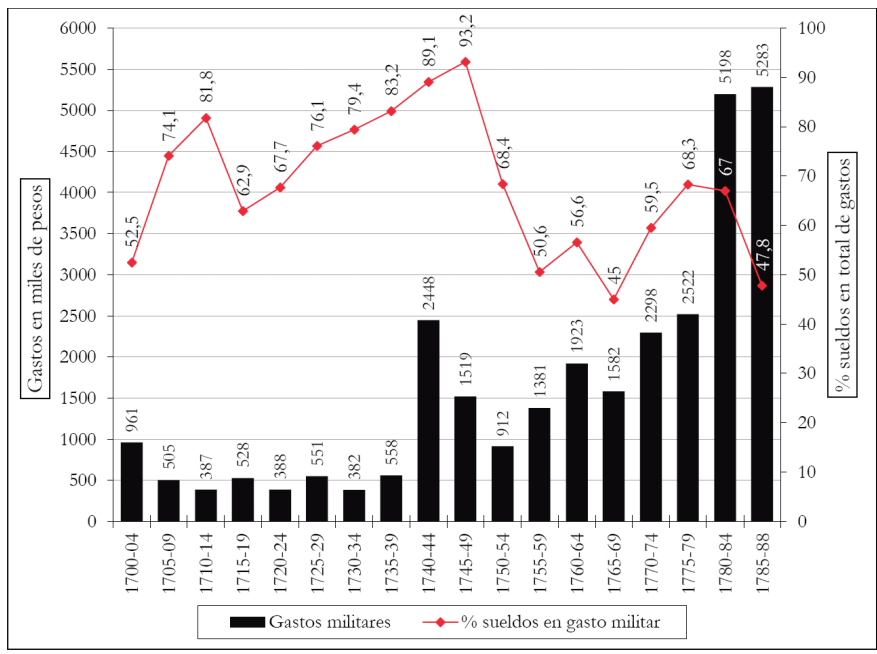

Fuente: Elaboración propia a partir de los datos de la tabla 1.

Ahora bien, la vida del Apostadero dependió de un conjunto de circunstancias entre la que sobresalía la disponibilidad presupuestal gracias a las transferencias del situado. Y esta estuvo sometida a los avatares propios de los ciclos de la economía del imperio, de las guerras en el Caribe y de los conflictos entre las distintas jurisdicciones políticas y militares que hacían presencia en Cartagena, las que se disputaban por controlar la distribución del situado y de algunos recursos de las Cajas Reales de la ciudad. Por ejemplo, el incremento del tráfico de barcos que había recibido un impulso del Reglamento de Libre Comercio de 1778, que debió redundar en la intensificación de los trabajos de reparaciones, tomó al Apostadero en serias dificultades económicas obligando a sus administradores a solicitar empréstitos. ${ }^{56}$ Desde finales de los años de 1770 hasta comienzos del decenio de 1790 el Apostadero sobrevivió con los 150.000 pesos que se le tenía asignado por disposición real. Sin embargo, a partir de 1796 empezó a crecer debido a que además de lo que le correspondía por concepto del situado fiscal, había logrado de parte de las Cajas Reales de Cartagena una suma superior a los 150.000 pesos, justificada por las guerras en el Caribe (tabla 2 y gráfico 2).

Esa especie de bonanza comenzó a revertirse a partir de 1808 en adelante, con la crisis del imperio por la invasión francesa a España, debido a que hubo que trasladar gruesas sumas de dinero a Madrid para poder sostener la guerra contra los invasores franceses. Esto afectó al situado que la ciudad recibía para su defensa militar. ${ }^{57} \mathrm{La}$ tabla 2 contiene los presupuestos aprobados por la Junta de la Marina para distintos

carpeta 11, f.778r.; leg.78, carpeta 12, f.778r.; leg.78, carpeta 13, ff.783r.-825r.; leg.93, carpeta 12, ff.190r.244v.; leg.102, carpeta 11, f.224r.; AGN, Sección Colonia (SC), Virreyes, leg.6, doc.27, f.1232r.; AGN, SC, Milicias y Marina (MM), leg.47, doc.30, f.447r.; AGN, SC, Miscelánea, leg.100, doc.38, f.631r.

${ }^{56}$ AGN, SC, Virreyes, leg.16, doc.65, ff.338-340v.

${ }^{57}$ Meisel Roca, "El situado de Cartagena de Indias a fines del Siglo de las Luces", 193-211. 
años del período 1760-1810. Aunque no se halló información sobre los presupuestos de 1800 a 1805 , por otros documentos se sabe que la tendencia fue ascendente hasta el año de la crisis política de 1808, cuando por las razones de los acontecimientos en todo el imperio las asignaciones presupuestales empezaron a decrecer.

Tabla 2. Presupuestos (pesos) Apostadero de la Marina de Cartagena, 1760-1810.

\begin{tabular}{|c|c|c|c|}
\hline Años & Presupuestos & Años & Presupuestos \\
\hline 1760 & 153.061 & 1792 & 150.000 \\
\hline 1761 & 144.956 & 1794 & 124.954 \\
\hline 1763 & 399.779 & 1795 & 123.058 \\
\hline 1767 & 112.784 & 1796 & 338.458 \\
\hline 1772 & 159.526 & 1797 & 218.224 \\
\hline 1774 & 233.337 & 1798 & 626.129 \\
\hline 1777 & 120.309 & 1799 & 214.976 \\
\hline 1778 & 198.034 & 1806 & 529.350 \\
\hline 1781 & 103.700 & 1808 & 536.503 \\
\hline 1787 & 272.533 & 1809 & 459.510 \\
\hline 1791 & 150.000 & 1810 & 258.403 \\
\hline
\end{tabular}

Fuentes: Elaboración del autor con base en AGN, SC, MM, leg.55, doc.54, ff.546r., 786r.; leg.54, doc.24, ff.179r.-184v., doc.81, 815r.-827r.; leg.60, doc.137, f.670v.; leg.62, doc.160, ff.800r.-805r.; leg.63, doc.36, ff.172r.-176v., doc.47, 250r., doc.51, 303r.-310r.; leg.114, doc.42, f.348r.; leg.47, doc.30, f.447r.; AGN, SAA I-16, GM, leg.27, carpeta única, ff.743r.-806r., 1044r.; leg.62, carpeta 1, ff.402r., 465r.; leg.73, carpeta 6, ff.983r., 985r.; leg.74, carpeta 8, f.760v.; leg.78, carpeta 11, f.778r.; leg.78, carpeta 12, f.778r.; leg.78, carpeta 13, ff.783r.-825r.; leg.93, carpeta 12, ff.190r.-244v.; leg.102, carpeta 11, f.224r.; AGN, SC, Virreyes, leg.6, doc.27, f.1232r.; AGN, SC, Miscelánea, leg.100, doc.38, f.631r.; Archivo Histórico Nacional de Madrid, Sección Diversos, fondo Colecciones, subfondo Colección de Documentos de Indias, legajo 32, expediente 33, 10 Imágenes.

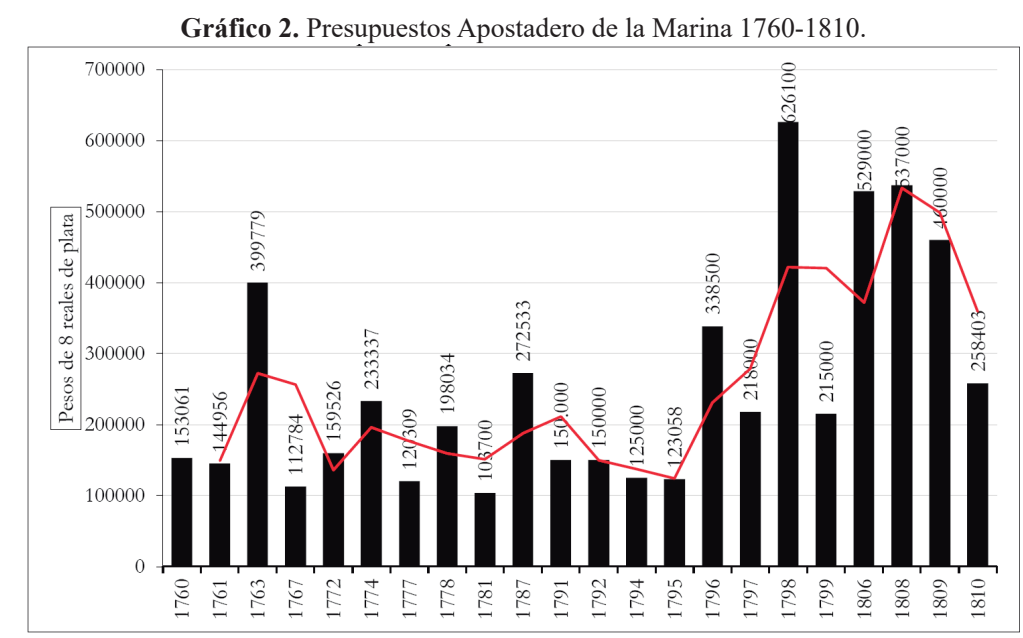

Fuente: Elaboración propia con base en la tabla 2.

Una salvedad para tener en cuenta al realizar los cálculos contenidos en la tabla 2 es que la participación de esas destinaciones en el total de gastos de cada frente dependía de distintos elementos que podían bajar o aumentar la participación del rubro 
de compras (en algunos casos los materiales eran propiedad del rey, y solo pagaban la mano de obra -por ejemplo, canteras y hornos de cal; obras de gran envergadura requerían de mayores compras). A su vez, esto subía o disminuía la porción de dinero destinada al pago de jornales y sueldos.

\section{Gasto en contratación de mano de obra en las defensas}

Las peculiaridades de cada frente de la defensa militar y la urgencia de los trabajos determinaban las asignaciones presupuestales para contratar trabajadores y pagar sus salarios. Las obras por realizar, el costo de los materiales y el tiempo invertido podían bajar o aumentar esa representación. Obras de gran envergadura requerían de mayores compras. Y como es de suponer, esto subía o disminuía la fracción de dinero destinada al pago de jornales y sueldos. En el caso de las fortificaciones el rubro de compras podía disminuir debido a que en algunos casos los materiales eran propiedad del rey (canteras y hornos de cal), y solo pagaban jornales a los trabajadores libres y raciones a esclavos del rey a presos destinados a trabajos forzados.

Los datos desagregados de los presupuestos del Apostadero de la Marina que aparecen en la tabla 2 indican que de las sumas anuales proporcionadas para el mantenimiento de la escuadra de guardacostas, un promedio del 30,3\% se dedicaba a salarios de los tripulantes, maestros mayores, maestranzas de carpinteros de ribera, calafates y veleros, y a los contratos de los artesanos asentistas de herrería, tornería y pintura y empleados del Arsenal..$^{58}$ Pero una cosa es la representación del total de sueldos y jornales en el presupuesto anual del Apostadero, y otra cosa es ver el costo de la mano de obra en labores específicas como el arreglo de los barcos, con gastos que dependían de los trabajos a realizar. En 1774 el arreglo de una balandra demandó una inversión de 2.304 pesos, y de estos el 30,5\% era calculado en el pago de jornales a carpinteros de ribera y a calafates. ${ }^{59} \mathrm{Y}$ durante tres meses de ese año se hicieron reparaciones en una fragata del rey destinada a guardacostas, la que había sufrido severos daños en su obra muerta, y el costo de la mano de obra de carpinteros de ribera y calafates representó el $75 \%$ de lo invertido. ${ }^{60}$ En 1800 en la construcción de una lancha cañonera se invirtieron 3.514 pesos, representando los jornales el $45,6 \%$ de esa suma. ${ }^{61}$

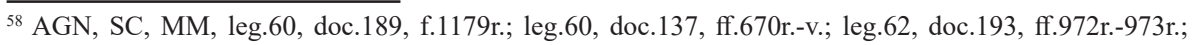
leg.47, doc.31, f.477r.; AGN, SAA I-16, GM, leg.56, carpeta 2, ff.159r.-160r., 229r.-230v.; leg.75, carpeta 1, ff.760r.-v.; leg.114, doc.42, ff.347r.-350v.; leg.73, carpeta 6, ff.972r.-975v.; leg.93, carpeta 15, ff.506r.611v; leg.93, carpeta 15, ff.610r..611v.; leg.98, carpeta 5, ff.775r.-837r.; AGN, SC, Virreyes, leg.6, doc.26, ff.1210r.-1240r; Archivo General de la Marina "Álvaro Bazán" (AGM-AB), Secretaría de Estado y Despacho de la Marina (SEDM), Sección Expediciones, Sub-Sección Expediciones a Indias (SE, SUBSEI), Cartagena de Indias, caja 46, doc.140, f.11.

${ }^{59}$ AGN, SC, MM, leg.55, doc.92, ff.949r.-v.

${ }^{60}$ AGN, SC, MM, leg.80, doc.34, ff.261r.-262r.

${ }^{61}$ AGN, SC, MM, leg.54, doc.42, ff.549r.-551v.
} 
Con base en un informe de Antonio de Arévalo, en el que se anotaba que entre 1779 y 1791 en la artillería se gastaron 333.414 pesos, ${ }^{62}$ podemos establecer que los jornales de la maestranza de los trabajadores representaban el 20\% de la sumatoria de los presupuestos de esos años. ${ }^{63}$ Pero en 1792 y 1793 esa participación bajó al $10,2 \% .{ }^{64}$ Estas fluctuaciones se debían a varias circunstancias. Una tiene que ver con el hecho de que la artillería tenía el taller más pequeño y el total de sus trabajadores, en momento de contratación de operarios eventuales, no llegaba a las tres decenas. Otra se relaciona con el estado de los equipos (cañones, cureñas y elementos para su uso y movilización) al momento que fue registrada la información. Y los informes parciales del administrador de la Real Fábrica de Cigarros indican que entre 1779 y 1785, y en los años de 1792, 1796, 1798 y 1799 alrededor del 33,3\% de lo gastado por años se destinaba al pago de los jornales de las trabajadoras. ${ }^{65}$ En estos casos las compras de insumos tenían una alta participación.

Cercanas a esas inversiones en mano de obra se encuentran los presupuestos calculados o ejecutados en otras construcciones y reparaciones de edificaciones. Por ejemplo, en 1755 fue tasado en un $29 \%$ el costo de los jornales en la construcción de un tendal con sus respectivas fraguas para los trabajos de herrería y fundición para las necesidades de las fortificaciones.$^{66}$ En 1792 se consideró que el pago a los trabajadores en las reparaciones del Cuartel de la Artillería representaba el 39,7\% del importe total de la obra ${ }^{67}$ Entre 1792 y 1794, los salarios cancelados en la construcción del Cuartel del Fijo (excluyendo a los aserradores empleados en la extracción de maderas a la altura de la parroquia de San Estanislao y el costo del terreno), representó el 29\% del monto total de los trabajos. ${ }^{68}$ Entre 1793 y 1794 en la construcción de las 24 Bóvedas de la muralla de Santa Catalina destinadas para alojar tropas, la suma de los jornales ascendió al 46\% del total de la inversión. ${ }^{69}$ En 1798, en el avalúo de los costos de las reparaciones de la Casa de la Aduana (actual alcaldía de la ciudad), el pago a los trabajadores se avaluó en el $28,6 \%$ de la inversión requerida, ${ }^{70}$ y en un nuevo cálculo

\footnotetext{
${ }^{62}$ AGS, SEDG, leg.7241, exp.31, imags.53-54. También ver: AGN, SAA I-16, GM, leg.23, carpeta 6, ff.235r., 237r., 238r., 239r., 240r., 242r., 243r., 248r., 266r., 268r., 286r., 323r.; leg.46, carpeta 2, ff.211r., 215r., 227r., 230r.; leg.44, carpeta 3, ff.108r.-110v.; leg.90, carpeta 1, ff.4r., 7r., 8r.; leg.100, carpeta 2, ff.288r.-290v.; leg.52, carpeta 4, f.637r.

${ }^{63}$ AGN, SC, MM, leg.61, doc.167, f.973r.; leg.72, doc.181, ff.875r.-883r.

${ }^{64}$ AGS, SEDG, leg.7242, exp.40, imags.275, 380.

${ }^{65}$ AGN, SAA, grupo II, fondo 7, Administración de Tabacos, Caja 73 Informes, carpeta 1, ff.3r.-17r.; AGN, SAA, grupo II, fondo 7, Administración de Tabacos, Caja 1 Nóminas, carpeta 2, ff.2r.-113r.; carpeta 2, ff.2r.-17r.; AGN, SAA, grupo II, fondo 7, Administración de Tabacos, Caja 2 Informes, carpeta 1, ff.94r.96r.; carpeta 2, ff.23r.-26v.; AGN, SAA I-16, GM, leg.45, carpeta 2, ff.93r.-94r.

${ }^{66}$ AGN, SC, MM, leg.81, doc.74, ff.558r.-559r.

${ }^{67}$ AGN, SC, MM, leg.65, doc.38, ff.257r.-258r.

${ }^{68}$ AGN, SC, MM, leg.21, doc.55, ff.488r.-491r.

${ }^{69}$ AGN, SC, MM, leg.65, doc.86, f.519r.

${ }^{70}$ AGN, SC, Aduanas, leg.21, doc.9, ff.294r.-299r. Este cálculo se mantuvo igual en 1801 cuando nuevamente se intentó hacer las reparaciones. AGN, SC, Aduanas, leg.10, doc.11, ff.509v.-511r.
} 
realizado en 1799 ascendió a 30,5\%. ${ }^{71}$ En 1802 en los trabajos de reparación del Claustro de La Merced los jornales representaron el 35\% de lo invertido. ${ }^{72}$ Con base en esos porcentajes podemos concluir que el promedio de la participación del costo del total de los trabajadores en la suma global de las inversiones en las construcciones y reparaciones señaladas estuvo alrededor del $32 \%{ }^{73}$

Sin embargo, esa relación era diferente en las fortificaciones situadas en varios puntos de la ciudad, en su bahía y en las costas de barlovento, teniendo que realizarse obras de distintas envergaduras al año, lo que a su vez determinaba una relación variable entre los costos de mano de obra y de compras en función de los trabajos que se llevaran a cabo y de la fase en que se encontraran. Y, aunque las fortificaciones contaban con un alivio en cuanto a la compra de algunos materiales (tenían a su disposición las canteras de Albornoz, Caño de Oro, Tesca y los Morros de propiedad real en las que solo pagaban la extracción de cantos de piedras, y sus necesidades de hierro y acero para fabricar y reparar herramientas, como también de pólvora para las canteras, eran proveídas por el almacén de la artillería), la mano de obra siempre era costosa en parte debido a que era el frente de la defensa que tuvo una alta demanda de trabajadores libres. En 1797, explicando las necesidades de las fortificaciones por la guerra con Inglaterra, el ingeniero Antonio de Arévalo, en sendas relaciones decía lo que había que traer de España, lo que se producía en Cartagena, y luego agregaba: “[...] la tercera es la más costosa, pero la más importante, como es la cantidad necesaria para el pago de los operarios que han de poner en uso y emplear los materiales mencionados en una y otra relación $[\ldots]^{\prime \prime} .^{74}$

En los trabajos en las fortificaciones se distinguen las grandes obras (construcción de fuertes y baterías y de largos tramos de muralla o de la escollera de Bocagrande), de los trabajos menores de reparaciones y mantenimientos. La compra de grandes cantidades de materiales para las primeras se reflejaba en su representación en el presupuesto total. Y aunque en las reparaciones también se adquirían materiales, el uso de la mano de obra tenía una mayor proporción en los presupuestos. Sin embargo, al igual que otros frentes de las defensas, variaba la participación de los salarios. Hubo años de considerables enganches de trabajadores y otros de reducción en la contratación de estos, lo que estaba en relación con las urgencias de las guerras y con la disponibilidad presupuestal. Así, durante la década de 1780 los trabajos fueron intensos, en especial después de la aprobación real en 1786 del plan de defensa que en 1778 había elaborado por el brigadier Agustín Crame, ${ }^{75}$ creció en algunos de sus años la vinculación de mano de obra libre. En 1782, con un presupuesto total que ascendió a 99.000 pesos, en los trabajos del cierre de Bocagrande y en las canteras de

\footnotetext{
${ }^{71}$ AGN, SC, Aduanas, leg.21, doc.19, ff.334r.-336r.

${ }^{72}$ AGN, SC, Real Audiencia-Bolívar, leg.1, doc.22, ff.763r.-v.

${ }^{73}$ Información sobre otras obras en Cartagena de Indias en Manuel Gámez, "Ingenieros militares y obras públicas. algunos ejemplos de Nueva Granada en el siglo XVIII”, Ars Longa, 27, (2018): 134-136.

${ }^{74}$ AGN, SC, MM, leg.3, doc.59, f.828v.

${ }^{75}$ AGN, SC, MM, leg.41, doc.25, ff.405r.-451v.
} 
Albornoz y Caño Loro que proveían de piedras, los jornales representaron el 50\%. ${ }^{76}$ De los 130.000 pesos invertidos en 1785 en los trabajos de fortificaciones, 117.400 pesos se gastaron en el cierre de Bocagrande y en las 3 canteras (Albornoz, Caño Loro y Tesca), representando el monto anual de los salarios el 53\% del total invertido. ${ }^{77}$

Pero el siguiente decenio sucedió lo contrario, con la excepción del tiempo de preparativos para las guerras con Francia (1792-1794) y con Inglaterra (17961802), que podían, de acuerdo con el cálculo del peligro a que se viera sometida la plaza fuerte, incrementar las inversiones e intensificar los trabajos durante algunos meses. En el segundo semestre de 1791, cuando ya las finanzas empezaban a mostrar agotamiento y se establecieron restricciones, las inversiones en el pago de un promedio de 39 trabajadores libres empleados en la construcción de la muralla de Santa Clara y en la cantera de Caño Loro se restringieron de forma significativa a un $21,5 \%{ }^{78}$ En 1793 cuando preparar las fortificaciones para la defensa de la plaza demandó una inversión de 83.528 pesos, un $178 \%$ más del presupuesto anual que era de 30.000 pesos. ${ }^{79}$ Y pocos años después, en 1797, en los preparativos por la guerra con los ingleses, se invirtieron en el primer semestre la cantidad de 25.219 pesos, con un promedio mensual de 329 trabajadores que laboraron en reparaciones de las baterías de San Andrés, San Pablo, San José de Bocachica, foso de la Media Luna, cocinas de la plaza de armas de Santa Catalina, cuidado de las bestias de carga, embarcaciones para transportar materiales y personal, cantera de Caño Loro y en la batería de Palo Alto, a la altura de La Boquilla. Del presupuesto gastado en el primer semestre de 1797 , el $66,1 \%$ correspondió al pago de jornales. A esto hay que agregar que en las labores de extracción de arenas del Canal de Bocachica y del foso del fuerte de San Fernando, adscritas a los presupuestos de las fortificaciones, se invirtieron 5.450 pesos, destinándose el $58,7 \%$ a los jornales de un promedio de 46 operarios. ${ }^{80}$

Cuando desaparecía la amenaza de guerra los problemas del déficit fiscal obligaban a recortar los presupuestos de las defensas. Para los años de 1780 las inversiones mensuales en fortificaciones eran de 8.000 pesos. ${ }^{81} 1791$ las se habían reducido a 5.000 pesos mensuales. Y en ese año, en el marco de la crisis fiscal del imperio y de las necesidades de realizar recortes en gastos militares para poder contar con fondos para el traslado de la población-fuerte de Caimán, en el Darién, el virrey José de Ezpeleta redujo los aportes para las fortificaciones de 5.000 a 2.500 pesos mensuales. $^{82}$ En nueve meses de ese año apenas se invirtieron 18.892 pesos en

\footnotetext{
${ }^{76}$ AGN, SAA I-16, GM, leg.24, carpeta 8, ff.149r.-518r.

${ }^{77}$ AGN, SAA I-16, GM, leg.34, carpeta 5, ff.73r.-446r., 624r.-672r.

${ }^{78}$ AGN, SAA I-16, GM, leg.59, carpeta 1, ff.564r.-718v.

${ }^{79}$ AGS, SEDG, leg.7241, exp.31, imag.75.

${ }^{80}$ AGN, SAA I-16, GM, leg.72, carpeta 3, ff.432r.-585r. Entre 1792 y 1797 se extrajeron 77.622 varas cúbicas de sedimentos del Canal de Bocachica, con un promedio de 12.604 varas cúbicas por año. AGN, SC, Miscelánea, leg.115, doc.11, ff.226r.-v.

${ }^{81}$ AGN, SC, MM, leg.70, doc.41, f.216r.

82 "Relación del estado del Nuevo Reino de Granada, que hace el Excelentísimo Señor José de Ezpeleta a su sucesor el Excelentísimo señor don Pedro de Mendinueta año de 1796”, en Eduardo Posada y Pedro Ibáñez (comps.), Relaciones de mando presentados por los gobernantes del Nuevo Reino de Granada (Bogotá:
} 
aumentar la altura de la muralla de Santa Clara y en los trabajos en la cantera de Caño Loro que la aprovisionaba de piedras, trabajando un promedio de 40 operarios por mes, al lado de 70 esclavos del rey y de 130 presos forzados. ${ }^{83}$

En los trabajos de reparaciones y otras obras menores eran mayores los gastos en jornales. En el primer semestre de 1782, en las labores en las fortificaciones de la plaza y de las situadas en la bahía, la mano de obra representó el 61,7\% del total invertido (4.759 pesos). ${ }^{84}$ Tres años después, en 1785, de la suma total de 130.000 pesos, 12.600 se emplearon en las reparaciones en la plaza y los exteriores (en la Muralla Real del Mar del Norte, batería de San Sebastián del Pastelillo, puentes del revellín de la Media Luna, Casa Real de la Aduana, Castillo de San Felipe, almacenes de la plaza y del Bosque, tendales de las murallas, composición del muelle y limpieza del foso del baluarte de Santo Domingo, carenas de embarcaciones menores que atendían las necesidades de las fortificaciones, transporte de materiales y trabajadores y la repartición de agua). De esa suma el $73,3 \%$ correspondió a jornales. ${ }^{85}$ En el segundo semestre de 1787 , de 8.568 pesos que se utilizaron en reparaciones en la plaza y sus alrededores, el $70,7 \%$ se destinó a jornales. ${ }^{86}$

Si al monto de los jornales sumamos el de las raciones diarias dadas a esclavos del rey y a los presos condenados a trabajos forzados, se incrementa la suma destinada a mano de obra. Por ejemplo, en diciembre de 1788 Antonio de Arévalo informaba a Madrid que cuando se inició la construcción de la escollera submarina de Bocagrande se contaba para ello con 171 esclavos del rey y 364 presos forzados, cuya manutención diaria costaba 100 pesos diarios (36.500 al año) a razón del 11/2 real que se les daba de ración diaria. Para 1778 esclavos y presos solo sumaban 176, el monto anual de las raciones ascendía a 11.800 pesos, lo que seguía considerando una cantidad alta. ${ }^{87} \mathrm{Y}$ aunque con el correr de los años el número de esclavos descendió, aumentó el de los presos. ${ }^{88}$ En 1751 los esclavos del rey que trabajaban en las fortificaciones, los presos forzados y los trabajadores libres se llevaron, en su orden, el 66\%, 27,1\% y $18,7 \%$ del empleado en el pago de mano de obra. Cinco años después, en 1756, ese orden había variado, correspondiendo a los trabajadores libres, esclavos y a los presos el $76 \%, 17,3 \%$ y el $6,8 \%$ respectivamente. ${ }^{89}$

Imp. Nacional, 1910), 394-395. También ver el informe que rindió a la corona en 1790: AGS, SEDG, leg.7242, exp.40, imags.39-49. En este informe decía que había recortado en 40.000 pesos los gastos en fortificaciones.

${ }^{83}$ AGN, SAA I-16, GM, leg.59, carpeta 1, ff.109r.-168r., 306r.-360v., 564r.-718r.

${ }^{84}$ Los trabajos fueron: desmonte de los manglares de los alrededores de la plaza; reparaciones de murallas, y de estacadas y rastrillos; conducción de agua a las baterías provisionales situadas a barlovento; cuidado de bestias empleadas en las obras; transporte de destacamentos a Bocachica y trabajos en las fraguas del parque y en el almacén. AGN, SAA I-16, GM, leg.24, carpeta 8, ff.526r.-616v.

${ }^{85}$ AGN, SAA I-16, GM, leg.34, carpeta 5, ff.73r.-446r., 624r.-672r.

${ }^{86}$ AGN, SAA I-16, GM, leg.45, carpeta 9, ff.705r.-782r.

${ }^{87}$ AGS, SEDG, leg.7236, exp.9, ff.66r.-69r.

${ }^{88}$ Ver cuadro sobre trabajadores libres, esclavos y presos en las defensas de Cartagena en: S. P. Solano, "Trabajadores, jornales, carestía y crisis política en Cartagena de Indias, 1750-1810", 555.

${ }^{89}$ AGN, SAA I-16, GM, leg.7, carpeta 17, ff.416r.-520r.; leg.6, carpeta 2, ff.4r.-116v. 
Para tener una idea aproximada acerca de cómo se reflejaban estas inversiones en la contratación de mano de obra, la tabla 3 incluye cantidades de trabajadores de los frentes de la defensa. En las fortificaciones aparecen los esclavos del rey y los presos condenados a trabajo forzados, los que no recibían salarios sino una ración diaria equivalente a $1 \frac{1}{2}$ reales por día. En este frente se observa una disminución del número de esclavos, un aumento de las cantidades de trabajadores libres hasta finales del siglo XVIII, cuando empezó a crecer el empleo de los presos debido a que la crisis fiscal obligó a reducir gastos en jornales. En el caso de la marinería, por encima de algunas fluctuaciones que se debieron a la presencia momentánea de grandes flotas de barcos, lo usual fue un promedio de 350 marineros, los que luego de la expedición de la ordenanza de 1772 de la matrícula de la mar, estuvo compuesto en su mayoría por hombres de la tierra. En este frente de la defensa hemos incluido a los trabajadores del Apostadero de la marina en que se comprenden a los carpinteros de ribera, calafates, veleros, motoneros, faroleros y jornaleros. La menor demanda de trabajadores era por parte de la artillería, aunque en algunas ocasiones aumentaba debido a los preparativos para las guerras.

Aunque es tema de otro estudio es necesario indicar que las implicaciones de las relaciones entre los trabajadores y los sistemas de defensa estaban más allá de lo estrictamente laboral. ${ }^{90}$ Tanto el pago de la mano de obra como de los contratos para realizar algunas obras y para proveer de materias primas irradiaba parte de los presupuestos de los frentes de la defensa entre distintos sectores de trabajadores, favoreciendo la movilidad social de algunas familias de artesanos, tema al que me he referido en otros artículos. ${ }^{91}$ Artesanos contratistas en herrería, pintura, y maestros en velámenes, farolería, motones, maestros de obra, sobrestantes, maestros carpinteros de ribera y de calafatería, mejoraron sus ingresos y se diferenciaron de los estratos más bajos de la población. ${ }^{92}$ En los libros de pago de derechos de alcabalas se registra que algunos de estos maestros (por ejemplo: Pedro Romero, Pedro de Medrano, Nicolás Delfín, Bruno Berrío y otros) incursionaron en el pequeño comercio de pulperías y cantinas, y hasta un almacén especializado, una ferretería establecida por Pedro Romero. También realizaron transacciones en bienes inmuebles y de cortas cantidades de esclavos. ${ }^{93}$

\footnotetext{
${ }^{90}$ Sergio Solano, "Historiografía sobre las relaciones entre las instituciones coloniales y los artesanos de Hispanoamérica a finales de la Colonia", Pensar la historia del trabajo y los trabajadores en América, siglos XVIII y XIX, coords. Sonia Pérez Toledo y Sergio Paolo Solano (Madrid/Frankfurt: AHILA/ Iberoamericana/Vervuert, 2016), 17-58.

${ }^{91}$ Sergio Paolo Solano, "Sistema de defensa, artesanado y sociedad en el Nuevo Reino de Granada", $92-$ 139; "Artesanos, jornaleros y formas concentradas de trabajo: el Apostadero de la Marina de Cartagena de Indias", 79-105; "Pedro Romero, el artesano", 151-170; "Trabajadores, jornales, carestía y crisis política en Cartagena de Indias, 1750-1810”, 549-488; "El costo social de la república", 243-287.

${ }^{92}$ Ver algunos nombres y los jornales que devengaban en el cuadro 3 del artículo "Trabajadores, jornales, carestía y crisis política en Cartagena de Indias, 1750-1810”, 558.

${ }^{93}$ AGN, SAA III-3, leg.80, Cartagena. Receptoría de alcabalas. Libro Auxiliar 1798-1799; AGN, SAA III3, leg.82, Cartagena. Receptoría. Libro común de cargo y data 1803; AGN, SAA III-3, leg.83, Cartagena. Receptoría de alcabalas. Libro Auxiliar 1802-1803; AGN, SAA III-3, leg.84, Cartagena. Receptoría. Libro auxiliar del ramo de pulperías. Pliego 1803-1804; AGN, SAA III-3, leg.920, Cartagena. Receptoría. Libro auxiliar 1807; AGN, SAA III-3, leg.96, Cartagena. Receptoría. Auxiliar del pliego $3^{\circ}$ de cargo 1808.
} 
Gasto fiscal e inversiones en mano de obra libre en Hispanoamérica. El caso de Cartagena...

Tabla 3. Trabajadores en los sistemas de defensa de Cartagena de Indias, 1751-1810.

\begin{tabular}{|c|c|c|c|c|c|c|c|c|c|c|c|c|c|c|c|c|c|c|c|}
\hline \multicolumn{20}{|c|}{ FORTIFICACIONES } \\
\hline & 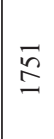 & 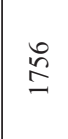 & $\stackrel{2}{\Sigma}$ & $\stackrel{尺}{\stackrel{2}{I}}$ & $\stackrel{\circ}{\stackrel{2}{\Sigma}}$ & $\underset{\substack{\infty \\
\stackrel{\infty}{\Sigma}}}{\stackrel{\infty}{=}}$ & $\stackrel{\infty}{\stackrel{\infty}{\beth}}$ & 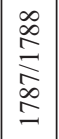 & § & ๙ૂ & જી & $\stackrel{2}{2}$ & $\hat{\Omega}$ & $\stackrel{\infty}{\varnothing}$ & $\underset{\infty}{\infty}$ & $\underset{\infty}{\infty}$ & $\underset{\infty}{\infty}$ & $\begin{array}{l}\stackrel{0}{0} \\
\infty \\
\stackrel{+}{+} \\
\infty \\
\infty\end{array}$ & 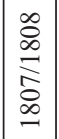 \\
\hline Libres & 16 & 708 & 38 & 531 & 384 & 410 & 460 & 226 & 298 & 236 & 417 & 387 & 521 & 113 & 195 & 71 & 63 & 182 & 215 \\
\hline Esclavos & 139 & 235 & 235 & 171 & 169 & 126 & 112 & 86 & 82 & 68 & 61 & 50 & 46 & 6 & 7 & 6 & 6 & 7 & 0 \\
\hline Presos & 75 & 102 & 110 & 364 & 360 & 243 & 151 & 148 & 135 & 153 & 151 & 146 & 298 & 247 & 207 & 208 & 153 & 163 & 170 \\
\hline Totales & 230 & 1.042 & 383 & 1.116 & 913 & 679 & 723 & 460 & 515 & 484 & 629 & 583 & 865 & 366 & 366 & 285 & 212 & 352 & 385 \\
\hline
\end{tabular}

\begin{tabular}{|c|c|c|c|c|c|c|c|c|c|c|c|c|c|c|c|c|c|c|c|c|c|c|c|c|}
\hline \multicolumn{25}{|c|}{ POSTADERO DE LA MARINA } \\
\hline$\stackrel{ \pm}{\stackrel{2}{\Sigma}}$ & $\begin{array}{l}\stackrel{*}{0} \\
\stackrel{0}{0}\end{array}$ & $\begin{array}{l}\text { ㅇ } \\
-\end{array}$ & $\stackrel{8}{I}$ & ڤo & 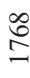 & 을 & $\stackrel{尺}{\stackrel{2}{I}}$ & $\stackrel{ }{\Sigma}$ & 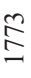 & $\underset{⿱}{\stackrel{\Xi}{Z}}$ & 令 & $\stackrel{\infty}{\stackrel{2}{\beth}}$ & 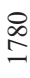 & $\stackrel{n}{\infty}$ & $\begin{array}{l}* \\
* \\
\infty \\
\infty \\
\Sigma\end{array}$ & $\stackrel{\Omega}{\Omega}$ & 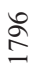 & $\hat{\Omega}$ & $\stackrel{\infty}{\stackrel{\Omega}{\beth}}$ & হ & $\stackrel{\curvearrowleft}{\infty}$ & $\stackrel{\infty}{\infty}$ & $\stackrel{\stackrel{े}{\infty}}{-}$ & \\
\hline
\end{tabular}

\section{Barcos y tripulaciones}

\begin{tabular}{|c|c|c|c|c|c|c|c|c|c|c|c|c|c|c|c|c|c|c|c|c|c|c|c|c|}
\hline 5 & 4 & 4 & 3 & 4 & 5 & 6 & 5 & 3 & 4 & 5 & 4 & 4 & 6 & 4 & 29 & 7 & 7 & 7 & 7 & 8 & 12 & 8 & 8 & 6 \\
\hline సે & $\stackrel{\tilde{\omega}}{\tilde{\sigma}}$ & 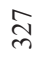 & $\frac{N}{\sim}$ & กิ & $\stackrel{\infty}{+}$ & $\overline{\widehat{\sigma}}$ & ర్ర & $\stackrel{\nabla}{\sim}$ & $\bar{ర}$ & iे & 후 & $\stackrel{\text { พ }}{m}$ & $\stackrel{\circ}{\circ}$ & $\underset{\infty}{\ddagger}$ & $\hat{8}$ & ? & $\stackrel{\circ}{\stackrel{\gamma}{\sigma}}$ & $\stackrel{?}{\stackrel{\gamma}{f}}$ & $\stackrel{8}{\circ}$ & $\stackrel{\infty}{+}$ & $\vec{\sim}$ & $\underset{+}{\infty}$ & $\frac{n}{n}$ & $\overline{\mathrm{d}}$ \\
\hline
\end{tabular}

\begin{tabular}{|c|c|c|c|c|c|c|}
\hline \multicolumn{7}{|c|}{ ARTILLERÍA } \\
\hline 1782 & 1788 & 1789 & 1792 & 1796 & 1804 & 1808 \\
\hline 62 & 45 & 22 & 37 & 46 & 37 & 36 \\
\hline
\end{tabular}

Fuentes: elaboración del autor a partir de: Fortificaciones: 1751: AGN, SAA I-16, GM, leg.6, carpeta 2, ff.8r.-90r.; 1756: AGN, SAA I-16, GM, leg.7, carpeta 17, ff.418r.-520r.; 1770: AGN, SC, Miscelánea, leg.120, doc.6, ff.21r.-30v.; 1776: AGN, SC, Mejoras Materiales, leg.21, doc.19, ff.495r.- 1782: AGN, SAA I-16, GM, leg.24, carpeta 8, ff.150r.-171v.; 1783: AGN, SAA I-16, GM, leg.27, carpeta 1, ff.831r.-850r.; 1785: AGN, SAA I-16, GM, leg.34, carpeta 5, ff.74r.-147v., 224r.-226v.; 1787-1788: AGN, SAA I-16, GM, leg.45, carpeta 9, ff.703r.-1103r.; 1790: AGN, SAA I-16, GM, leg.59, carpeta 1, ff.4r.-100r.; 1791: AGN, SAA I-16, GM, leg.59, carpeta 1, ff.564r.-791v.; 1792: AGS, SEDG, leg.7239, exp.20, f.124r.; 1793: AGS, SEDG, leg7240, exp.31; 1796: AGN, SC, MM, leg.8, doc.34, ff.606r.-610v.; 1797: AGN, SAA I-16, GM, leg.72, carpeta 3, 432r.-583v.; AGN, SC, Miscelánea, leg.15, doc.111, f.230r.; 1800: AGN, SAA I-16, GM, leg.85, carpeta 1, ff.15r.42v., 120r.-130r., 154r.-165r.; 1801: AGN, SC, Virreyes, leg.12, doc.7, f.146r.; 1802: AGN, SC, MM, leg.3, doc.58, ff.801r.-821r.; AGN, SC, MM, leg.5, doc.7, f.132r.; AGN, SC, Miscelánea, leg.132, doc.14, f.100r.; 1803: AGN, SC, Aduanas-Cartas, leg.8, doc.214, f.842r.; 1804/05: AGN, SAA I-16, GM, leg.90, carpeta 2, ff.216r.-292v.; 1807: AGN, SAA I-16, GM, leg.100, carpeta 2, ff.460r.-469v.; 1808: AGN, SC, MM, leg16, doc.189, f.1032v. Apostadero de la marina: 1754: AGN, SC, MM, leg.80, doc.14, f.98r.; 1760: AGN, SC, MM, leg.62, doc.154, f.803r.; 1765: AGN, SC, MM, leg.60, doc.20, f.123r.; 1766: AGN, SC, MM, leg.54, doc.51, f.611r.; 1767: AGN, SC, MM, leg.53, doc.128, f.834r.; 1768: AGN, SC, MM, leg.74, doc.37, f.177r.; 1769: AGN, SC, MM, leg.50, doc.93, f.1054r.; 1770: AGN, SC, MM, leg.80, doc.34, f.230r.; AGN, SC, MM, leg.80, doc.39, f.314r; 1771: AGN, SC, Aduanas-Cartas, leg.5, doc.168, f.903; 1773: AGN, SC, MM, leg.81, doc.19, ff.112r.; 1774: AGN, SC, MM, leg.81, doc.89, f.612r.; AGN, SC, MM, leg.63, doc.36, ff.172r.-175v.; AGN, SC, MM, leg.80, doc.52, f.408r.; AGN, SC, Miscelánea, leg.129, doc.81, ff.536r.-537r.; 1775: AGN, SC, MM, leg.62, doc.193, ff.972r.-973r.; 1777: AGN, SAA I-16, GM, leg.16, carpeta 23, ff.265r.-273v.; 1778: AGN, SAA I-16, GM, leg.16, carpeta 3, f.28r.; carpeta 5, f.77r.; carpeta, 8, f.121r.; carpeta 12, f.166r.; AGN SC, MM, leg.26, doc.11, ff.152r.-153r., 156r.; 1780: AGN, SAA I-16, GM, leg.27, carpeta 1, ff.831r.-850r.; 1783: AGN, SAA I-16, GM, leg.28, carpeta 1, ff.54r.-57v.; 1785: AGN, SAA I-16, GM, leg.33, carpeta única, ff.218r.-243v.; 1786: AGI, Estado, legajo 54, expediente 4; AGN, SAA I-16, GM, leg.42, carpeta 9, ff.468r.-493v.; AGN, SC, Mejoras Materiales, leg.20, doc.8, ff.830r.-v.; 1787: AGN, SAA I-16, GM, leg.42, carpeta 9, ff.482v.-483r.; AGN, SAA I-16, GM, leg.43, carpeta única, ff.1r.-1131r.; 1788: AGN, SAA I-16, GM, leg.48, carpeta 11, ff.895r.-896v.; 1789: AGN, SAA I-16, GM, leg.48, carpeta 11, ff.898r.-902v.; 1792: AGN, SAA I-16, GM, leg.56, carpeta 2, ff.676r.776r.; 1793: AGS, SDEG, leg.7242, exp.40, imgs.289-295; 1796: AGN, SC, MM, leg.114, doc.42, ff.347r.-350v.; 1797: AGN, SAA I-16, GM, leg.73, carpeta 6, ff.972r.-985r.; 1798: AGN, SC, MM, leg.60, doc.180, f.1079r.-v.; AGN, SC, Virreyes, leg.6, doc.27, ff.1229r.-1231r., 1233r.; 1799: AGM-AB, SEDM, SE, SUBS-EI, Varios Asuntos, caja 31, doc.105; 1805: AGM-AB, SEDM, SE, SUBS-EI, Comandante de Marina de Cartagena de Indias, caja 37, doc.059; 1808: AGN, SAA I-16, GM, leg.98, carpeta 5, ff.775r.-v.; 1809: AGN, SC, MM, leg.47, doc.31, ff.481r.-483r., 485r., 489r.; 1810: AGM-AB, SEDM, SE, SUBS-EI, fondo Cartagena de Indias. caja 46, doc.140, ff.22-24; 1810: AGM-AB, SEDM, SE, SUBS-EI, Varios Asuntos, caja 31, doc.105, f.3; 1810: AGN, SC, MM, leg.63, doc.47, f.250r. * En este año estuvo en la escuadra guardacostas un navío de línea de 68 cañones y un buen número de tripulantes y una fragata. ** El aumento de la cantidad de barcos y tripulantes en 1786 se debió al arribo de las embarcaciones que transportaban a los regimientos de la Corona y de la Princesa, que retornaban a España luego de la guerra con Inglaterra (1778-1783), los que permanecieron en la ciudad por varios meses. Maestranza de la artillería: 1788: AGN, SAA I-16, GM, leg.44, carpeta 3, ff.108r.-110v.; AGN, SAA I-16, GM, leg.46, carpeta 2, ff.211r., 215r., 227r., 230r.; 1789: AGN, SAA I-16, GM, leg.52, carpeta 4, ff.637r.; 1793: AGS, SEDG, leg.7236, exp.9; leg.7240, exp.31; 1797: AGN, SC, MM, leg.3, doc.59, ff.822r.-860v.; 1804: AGN, SAA I-16, GM, leg.90, carpeta 1, ff.4r., 7r., 8r.; 1808, AGN, SAA I-16, GM, leg.100, carpeta 2, ff.288r.-290v.; AGN, SAA I-16, GM, leg.56, carpeta 2, ff.676r.-776r.; AGS, SDEG, leg.7236, exp.9; AGN, SAA I-16, GM, leg.7239, exp.20; AGN, SAA I-16, GM, leg.7240, exps.21 y 41. 
El sustento de muchos hogares dependió de que algunos de sus miembros trabajaran en las defensas. Según el censo de población de 1777, en cuatro de los cinco barrios de la ciudad había 4.392 hombres libres, y si nos atenemos a las edades estipuladas para prestar el servicio miliciano (15 y 54 años), de aquella cifra 2.162 hombres, el 49,2\% del total de la población masculina, estaban incluidos en las edades aptas para trabajar. ${ }^{94}$ Por otra parte, si tomamos las cifras de los trabajadores libres de los sistemas de defensa correspondientes a $1782,{ }^{95}$ veremos que un total de 771 trabajaba en esos sistemas, cantidad significativa pues representaba el $36 \%$ del número total que hemos indicado como la población masculina potencialmente en capacidad de trabajar. Y si contabilizamos a los hombres libres cabezas de familia (registrados como casados) que aparecen en el censo de 1777, el total de vecinos era de 1.794, correspondiendo a cada familia un cociente de 7 personas. En consecuencia, un total de 5.397 habitantes que en ese año dependían de los trabajos en los sistemas defensivos, lo que equivalía al 39,4\% de la población total de la ciudad. Y si continuamos haciendo ese ejercicio, de los 1.354 trabajadores ${ }^{96}$ de los sistemas de defensa correspondientes a los años de 1808-1809, representaban el 8\% del total de la población del estimativo de 17.000 habitantes que en 1805 calculó el ingeniero Manuel de Anguiano, ${ }^{97}$ y si cada uno tenía 7 personas a su cargo, el total era de casi el 55,8\% de la cifra global estimada por ese ingeniero.

Sin embargo, debe tenerse en cuenta que para muchos trabajadores las colocaciones no fueron constantes, y así como podían ser enganchados en las distintas obras, en otras ocasiones padecieron el tiempo muerto, la falta de demanda, lo que fue, y sigue siendo una característica del trabajo en las obras públicas, y quizá una constante de buena parte de las formas de trabajo de las sociedades del Antiguo Régimen. Las continuas guerras durante el periodo que estudio (el 35\% del total de los años estudiados: 1750-1810) con los subsiguientes periodos de paz, y el creciente déficit fiscal determinaron intensos periodos de trabajos y de demanda de mano de obra, seguidos por otros de caída de los trabajos. Esto, a su vez determinó oscilaciones en las contrataciones de trabajadores, en especial en las fortificaciones y en la maestranza de artillería, mientras que se mantuvo estable en el Apostadero de la marina. La crisis fiscal del imperio manifestada desde mediados de los años de 1790 y profundizada durante la crisis de la corona de 1808 en adelante, afectó a todos los trabajadores. La no afluencia del situado para los sistemas de defensa, las precarias condiciones de las cajas reales de la ciudad y los enfrentamientos entre distintos sectores de poder en torno a las prioridades de las inversiones de las escasas rentas afectaron la demanda de trabajos. Esto implicaba el desplazamiento de los trabajadores, en especial de los

\footnotetext{
${ }_{94}$ María Aguilera y Adolfo Meisel Roca, Tres siglos de historia demográfica de Cartagena de Indias (Cartagena: Banco de la República, 2009), 21-42. Para los resúmenes consultar: AGN, SC, MM, leg.141, doc.122, f.1081r.; AGN, Sección Colecciones, Enrique Ortega Ricaurte, Serie Censos de Poblaciones, caja 12, carpeta 1, ff.11r.-12v.; AGN, Sección Mapas y Planos, fondo Mapoteca 7, referencia 1353, f.21r.

${ }^{95}$ AGN, SAA I-16, GM, leg.24, carpeta 8, ff.150r.-171v.; leg.27, carpeta 1, ff.831r.-850r.

${ }^{96}$ AGN, SAA I-16, GM, leg.100, carpeta 2, ff.460r.-469v.; AGN, SC, MM, leg16, doc.189, f.1032v.

${ }^{97}$ Manuel de Anguiano, "Descripción geográfica, militar y política de la ciudad de Cartagena de Indias", en Servicio Geográfico del Ejército (España), Depósito de la Guerra, Archivo de Planos, Estante J, Tabla 5, Cartera 2a, Sección A, No. 7, 1805, f.IIv.
} 
no calificados, de los peones o jornaleros, por distintos oficios, lo que también fue otra característica del trabajo preindustrial.

\section{Conclusiones preliminares}

Las investigaciones sobre los tres siglos de dominio español en Hispanoamérica adquieren mayor complejidad a partir de los recientes estudios sobre el gasto fiscal, los conflictos de competencias entre jurisdicciones administrativas de la monarquía para determinar el manejo de recursos y las áreas de inversiones, la irradiación de ese gasto entre los distintos rubros que componían las finanzas reales, el concebir la inversión militar no como algo anómalo sino como congénita al Estado fiscal militar. Estos logros historiográficos deben servir de punto de partida para analizar las implicaciones sociales de los recaudos fiscales y de los traslados de dineros entre las cajas reales de distintas provincias. Los datos que he aportado sobre las inversiones en sistemas de defensa y gastos en contrataciones de mano de obra libre en Cartagena de Indias indican que las actividades portuarias y de la defensa militar implicaron labores productivas en las esferas de la circulación comercial y de producción y mantenimiento de dispositivos militares, las que demandaron trabajo libre asalariado desde antes del advenimiento del capitalismo moderno. Y esas actividades se incrementaban en épocas de guerras que hacían de los mares sus principales escenarios, como sucedió durante la segunda mitad del XVIII cuando los enfrentamientos de los imperios europeos hicieron del mar Caribe el principal escenario de las confrontaciones navales, obligando a la Corona española a militarizar a sus posesiones de ultramar, invirtiendo grandes sumas en dinero en los sistemas de defensa de las ciudades portuarias. Eso explica que durante ese periodo las labores en las defensas de Cartagena y el empleo de trabajadores asalariados alcanzaran grandes proporciones.

Por eso, no podemos entender la sociedad de la Cartagena del siglo XVIII por fuera de las políticas militares de la corona española, y del obligado traslado de dineros entre las provincias y de la destinación de recursos de las cajas reales locales para las defensas. Cartagena contó con un complejo mundo laboral, que estuvo mucho más allá del pequeño taller artesanal de un maestro artesano con un corto número de oficiales y aprendices, y ello incluyó, y aunque no sea objeto de este artículo es pertinente señalarlo, la Real Fábrica de Cigarros de Cartagena que existió de forma continua entre 1778 y 1808 , empleando un promedio anual de 210 mujeres. $^{98}$

Pero como todo mundo laboral ligado a obras públicas en las sociedades del Antiguo Régimen tanto las necesidades de las defensas como las fluctuaciones a nivel de las inversiones en ellas generaron periodos de alto y bajo empleo, y, por tanto,

\footnotetext{
${ }_{98}$ AGN, SAA, grupo II, fondo 7, Administración de Tabacos, caja 2, Informes, carpeta 2, ff.23r.-26v.; AGN, SAA, grupo II, fondo 7, Administración de Tabacos, Caja 1 Nóminas, carpeta 2, ff.2r.-113r.; AGN, SAA, grupo II, fondo 7, Administración de Tabacos, caja 73 Informes, carpeta 1, ff.3r.-17r.; AGN, SAA, grupo II, fondo 7, Administración de Tabacos, caja 1 Nóminas, carpeta 2, ff.2r.-17r.; AGN, SAA, grupo II, fondo 7, Administración de Tabacos, caja 2 Informes, carpeta 1, ff.94r.-96r AGN, SAA, grupo II, fondo 7, Administración de Tabacos, caja 45, carpeta 2, ff.172v., 247r.-262v.; AGN, SAA, grupo II, fondo 7 , Administración de Tabacos, caja 42, carpeta 1, ff.103r.-104v.
} 
de desplazamiento estacional de la mano de obra, en especial de la no calificada, hacia otras actividades. Asimismo, algunos trabajadores con altas calificaciones se estabilizaron en sus colocaciones, mejoraron sus ingresos, originándose un proceso de diferenciación con relación a la plebe de una franja de trabajadores con mejores ingresos y que tuviesen estilos de vida que les granjeaban el reconocimiento social.

\section{Bibliografía}

\section{Fuentes primarias}

\section{Fuentes de archivo}

Archivo General de la Nación-Colombia (AGN), Sección Colonia (SC), fondos: Aduanas; Mejoras Materiales; Milicias y Marina (MM); Miscelánea; Policía; Real Audiencia-Bolívar; Virreyes. Sección Archivo Anexos (SAA), Grupo I, fondo 16, Guerra y Marina (GM). AGN, SAA, Grupo II, fondo 7, fondo Administración de Tabacos. AGN, SAA, grupo III, fondo 3, Cartagena. Receptoría de alcabalas. Sección Colecciones, Enrique Ortega Ricaurte, Serie Censos de Poblaciones. Sección Mapas y Planos, fondo Mapoteca 7.

Archivo General de Simancas, Secretaría de Estado y Despacho de Guerra (AGS, SEDG).

Archivo General de la Marina "Álvaro Bazán” (AGM-AB), Secretaría de Estado y Despacho de la Marina (SEDM), Sección Expediciones, Sub-Sección Expediciones a Indias (SE, SUBS-EI).

Archivo Histórico Nacional de Madrid, Sección Diversos, fondo Colecciones, subfondo Colección de Documentos de Indias.

Anguiano, Manuel de. "Descripción geográfica, militar y política de la ciudad de Cartagena de Indias", en Servicio Geográfico del Ejército (España), Depósito de la Guerra, Archivo de Planos, Estante J, Tabla 5, Cartera 2a, Sección A, No. 7, 1805.

\section{Fuentes secundarias}

\section{Libros}

Aguilera, María y Meisel Roca, Adolfo. Tres siglos de historia demográfica de Cartagena de Indias. Cartagena: Banco de la República, 2009.

Alves, Angelo y Sánchez Santiró, Ernest (coords.). Guerra y fiscalidad en la Iberoamérica colonial (siglos XVII-XIX)/Guerra e fiscalidade na Ibero-América colonial (séculos XVII-XIX). Minas de Gerais/México: Universidade Federal de Juiz de Fora/Instituto Mora, 2012. 
Gasto fiscal e inversiones en mano de obra libre en Hispanoamérica. El caso de Cartagena...

Andrade, Germán. Un mar de intereses. La producción de pertrechos navales en Nueva España, siglo XVIII. México: Instituto Mora, 2006.

Brewer, John. The sinews of power: War, money and the English State, 1688-1783. Londres: Unwin, 1989.

Celaya, Yovana. Alcabalas y situados. Puebla en el sistema fiscal imperial 16381742. México: Colmex/Fideicomiso de Historia de las Américas, 2010.

Clayton, Lawrence. Los astilleros de Guayaquil colonial. Guayaquil: Casa de la Cultura Ecuatoriana Núcleo del Guayas, 1978.

Elliot, John. Imperios del Mundo Atlántico. España y Gran Bretaña en América, 1492-1830. Madrid: Taurus, 2006.

Halperin Donghi, Tulio. Guerra y finanzas en los orígenes del Estado argentino 17911850. Buenos Aires: Prometeo, 2005.

Johnson, Lyman. Los talleres de la revolución. La Buenos Aires plebeya y el mundo del Atlántico, 1776-1810. Buenos Aires: Ed. Prometeo, 2013.

Kuethe, Allan. Reforma Militar y sociedad en la Nueva Granada, 1773-1808. Bogotá: Banco de la República, 1993.

Laviana, María. Guayaquil en el siglo XVIII. Recursos naturales y desarrollo económico. Sevilla: CSIC/EEHA, 1987.

Luque, Emilio. Arquitectura y mano de obra en el Uruguay colonial. Sobrestantes, herreros, carpinteros, albañiles y picapedreros. Zaragoza: Libros Pórtico, 2010.

Marco Dorta, Enrique. Cartagena de Indias. Puerto y plaza fuerte. Bogotá: Fondo Cultural Cafetero, 1988.

Marchena, Juan. La institución militar de Cartagena de Indias 1700-1810. Sevilla: EEHA, 1982.

Marichal, Carlos. La bancarrota del virreinato. Nueva España y las finanzas del imperio español, 1780-1810. México: FCE/Colmex, 1999.

Morales, Carlos. Mercantilismo y crecimiento económico en el virreinato del Perú. La organización del estanco del tabaco. Lima 1750-1800. Lima: Universidad Nacional Mayor de San Marcos, 2015.

Muriel, Josefina. Hospitales de la Nueva España. Tomo II. Fundaciones de los siglos XVII y XVIII. México: UNAM/Cruz Roja, 1991. 
North, Douglass. Instituciones, cambio institucional y comportamiento económico. México: FCE, 1995.

Pinzón, Guadalupe. Acciones y reacciones en los puertos del Mar del Sur. Desarrollo portuario del Pacífico novohispano a partir de sus políticas defensivas, 1713 1789. México: UNAM/Instituto Mora, 2011.

Pinzón, Guadalupe. Hombres de mar en las costas novohispanas. Trabajos, trabajadores y vida portuaria en el departamento maritimo de San Blas (siglo XVIII). México: UNAM, 2014.

Quiroz, Enriqueta. Economía, obras públicas y trabajadores urbanos Ciudad de México: 1687-1907. México: Instituto Mora, 2016.

Sánchez de Tagle, Esteban. Los dueños de la calle. Una historia de la vía pública en la época colonial. México: INAH, 1997.

Sánchez de Tagle, Esteban. Del gobierno y su tutela. La reforma a las haciendas locales del siglo XVIII y el cabildo de México. México: INAH, 2014.

Serrano Álvarez, José. Fortificaciones y tropas. El gasto militar en Tierra Firme, 1700-1788. Sevilla: CSIC, 2004.

Serrano Álvarez, José. Ejército y fiscalidad en Cartagena de Indias. Auge y declive en la segunda mitad del siglo XVII. Bogotá: El Áncora Eds., 2006.

Serrano Álvarez, José. El astillero de La Habana en el siglo XVIII. Historia y construcción naval (1700-1805). Madrid: Ministerio de Defensa, 2018.

Silva, Jorge. La reforma fiscal de los ayuntamientos novohispanos (1765-1812). Madrid: Universidad Michoacana/Universidad de Alcalá/Marcial Pons, 2015.

Stein, Stanley y Stein, Bárbara. La herencia colonial de América Latina. México: Siglo XXI, 1980.

Tovar, Hermes. El imperio y sus colonias: las cajas reales de la Nueva Granada en el siglo XVI. Bogotá: AGN, 1999.

Valdez-Bubnov, Iván. Poder naval y modernización del Estado: política de construcción naval española (siglos XVI-XVIII). México: UNAM/Bonilla Artigas/ Iberoamericana, 2011.

Valle, Guillermina. Finanzas piadosas y redes de negocios. Los mercaderes de la Ciudad de México ante la crisis de Nueva España, 1804-1808. México: Instituto Mora, 2012. 
Gasto fiscal e inversiones en mano de obra libre en Hispanoamérica. El caso de Cartagena...

Zapatero, Juan M. Historia de las fortificaciones de Cartagena de Indias. Madrid: Centro Iberoamericano de Cooperación/Ministerio de Asuntos Exteriores, 1979.

\section{Capítulo de libro}

Arévalo, Antonio de. "Proyecto de cerrar la abertura de Bocagrande y resguardar las murallas del norte de Cartagena de Indias, por don Antonio de Arévalo, 1769", en Colección de documentos inéditos sobre la geografía y la historia de Colombia. Antonio B. Cuervo (comp.). Bogotá: Imp. Zalamea, 1891, 220-248.

Calderón, Andrés y Dobado, Rafael. "Siete mitos acerca de la historia económica del mundo hispánico". Pintura de los reinos. Identidades compartidas en el mundo hispánico. Miradas varias, siglos XVI-XIX. Rafael Dobado y Andrés Calderón (coords.). Barcelona: Real Academia de la Historia/Fomento Cultural Banamex/ Academia Mexicana de la Historia, 2012, 75-103.

Contreras, Carlos. "El gasto público en el virreinato del Perú, 1700-1820". El gasto público en los imperios ibéricos, siglo XVIII. Ernest Sánchez Santiró (coord.). México: Instituto Mora/Conacyt, 2015, 167-204.

Engerman, Stanley, Sokoloff, Kenneth and Haber, Stephen. "Factor Endowments and Institutions", Economic Development in the Americas since 1500. Endowments and Institutions. Stanley E. Engerman and Kenneth Sokoloff. New York: Cambridge University Press, 2012, 31-93.

Flores, Ramiro. "Fiscalidad y gastos de gobierno en el Perú Borbónico". Compendio de historia económica del Perú. Tomo 3. Economía del período colonial tardío. Carlos Contreras (ed.). Lima: Banco Central de la Reserva del Perú/IEP, 2010, 295-380.

Flores, Ramiro. "Los situados peruanos: desde Chile hasta Panamá (1700-1800)". El secreto del imperio español: los situados coloniales en el siglo XVIII. Carlos Marichal y Johanna von Grafenstein (coords.). México: Colmex/Instituto Mora, 2012, 33-59.

García, Marta. "Impacto de las fundaciones piadosas en la sociedad queretana (siglo XVIII)". Cofradias, capellanías y obras pías en la América colonial. María Martínez, Gisela von Wobeser y Juan Muñoz (coords.). México: UNAM, 1998, 247-262.

Grafenstein, Johanna von. "Políticas y prácticas de abasto de las plazas militares españolas en el Caribe". El Caribe: región, frontera y relaciones internacionales. Johanna von Grafenstein y Laura Muñoz (coords.). México: Instituto Mora, 2000, 257-314.

Grafenstein, Johanna von. "La provisión de las armadas y presidios de las islas de barlovento: intereses novohispanos versus habaneros (1760-1780)". Mercaderes, 
comercio y consulados de Nueva España, 1663-1810. Guillermina del Valle (coord.). México: Instituto Mora, 2003, 67-97.

Grafenstein, Johanna von. "Situado y gasto fiscal: la real caja de México y las remesas para gastos militares en el Caribe, 1756-1783". Guerra y fiscalidad en la Iberoamérica colonial (siglos XVII-XIX)/Guerra e fiscalidade na Ibero-América colonial (séculos XVII-XIX). Angelo Alves y Ernest Sánchez Santiró (coords.). Minas de Gerais/México: Universidade Federal de Juiz de Fora/Instituto Mora, 2012, 115-142.

Grafenstein, Johanna von. "Provisión de víveres para la real armada y presidios de Barlovento en el siglo XVIII: su arrendamiento a particulares o administración directa". La fiscalidad novohipana en el imperio español. Conceptualizaciones, proyectos y contradicciones. María Martínez, Ernest Sánchez Santiró y Matilde Souto (coords.). México: Instituto Mora/Conacyt/UNAM, 2015, 105-138.

Irigoin, Alejandra y Grafe, Regina. “Absolutismo negociado: la trayectoria hispánica en la formación del Estado y el imperio". El secreto del imperio español: los situados coloniales en el siglo XVIII. Carlos Marichal y Johanna von Grafenstein (coords.). México: Colmex/Instituto Mora, 2012, 295-339.

Jumar, Fernando y Sandrín, María E. "El gasto público como dinamizador de la economía local. Rio de la Plata, en la primera mitad del siglo XVIII". El gasto público en los imperios ibéricos, siglo XVIII. Ernest Sánchez Santiró (coord.). México: Instituto Mora/Conacyt, 2015, 205-272.

Loreto, Rosalva. "La caridad y sus personajes: las obras pías de don Diego Sánchez Peláez y doña Isabel de Herrera Peregrina. Puebla, siglo XVIII". Cofradias, capellanías y obras pías en la América colonial. María Martínez, Gisela von Wobeser y Juan Muñoz (coords.). México: UNAM, 1998, 263-280.

Marchena, Juan. "Capital, créditos e intereses comerciales a fines del periodo colonial: los costos del sistema defensivo americano. Cartagena de Indias y el sur del Caribe". Soldados del rey. El ejército borbónico en América colonial en vísperas de la independencia. Allan Kuethe y Juan Marchena (eds.). Castelló de la Plana: Universitat Jaume I, 2005, 161-214.

Marichal, Carlos. "La iglesia y la crisis financiera del virreinato, 1780-1808: apuntes sobre un tema viejo y nuevo". Hacienda y política: las finanzas públicas y los grupos de poder en la primera República Federal mexicana. José Serrano Ortega y Luis Jáuregui (eds.). Zamora: Colmich/Instituto Mora, 1998, 97-161.

Marichal, Carlos. "Beneficios y costos fiscales del colonialismo: las remesas americanas a España, 1760-1814". Finanzas y política en el mundo iberoamericano: del Antiguo Régimen a las naciones independientes 1754-1850. Ernest Sánchez Santiró, Luis Jáuregui y Antonio Ibarra (coords.). México: UNAM/Instituto Mora/ Universidad Autónoma del Estado de Morelos, 2001, 29-61. 
Gasto fiscal e inversiones en mano de obra libre en Hispanoamérica. El caso de Cartagena...

Marichal, Carlos y Grafenstein, Johanna von (coords.). El secreto del imperio español: los situados coloniales en el siglo XVIII. México: Colmex/Instituto Mora, 2012.

Marichal, Carlos y Souto, Matilde. "La Nueva España y los financiamientos del imperio español en América: los situados para el Caribe en el siglo XVIII". El secreto del imperio español: los situados coloniales en el siglo XVIII. Carlos Marichal y Johanna von Grafenstein (coords.). México: Colmex/Instituto Mora, 2012, 92-93.

Meisel Roca, Adolfo. “¿Situado o contrabando? Las bases económicas de Cartagena de Indias a fines del Siglo de las Luces". El Golfo-Caribe y sus puertos. Tomo I, 1600-1850. Johanna von Grafenstein (coords.). México: Instituto Mora, 2006, 43-90.

Meisel Roca, Adolfo. "El situado de Cartagena de Indias a fines del Siglo de las Luces". El secreto del imperio español: los situados coloniales en el siglo XVIII. Carlos Marichal y Johanna von Grafenstein (coords.). México: Colmex/Instituto Mora, 2012, 193-211.

Meisel Roca, Adolfo. "Los ingresos fiscales y la economía del virreinato de Nueva Granada, 1761-1800". Iberoamérica y España antes de la independencia, 17001820. Crecimiento, reformas y crisis. Jorge Gelman, Enrique Llopis y Carlos Marichal (coords.). México: Instituto Mora/Conacyt/Colmex, 2014, 265-305.

Pérez Vejo, Tomás. "La difícil herencia: hispanofobia e hispanofilia en el proceso de construcción nacional mexicano". Los caminos de la ciudadanía. México y España en perspectiva comparada. Manuel Suárez y Tomás Pérez Vejo (eds.). Madrid: Universidad de Cantabria, 2010, 219-230.

"Relación del estado del Nuevo Reino de Granada, que hace el Excelentísimo Señor José de Ezpeleta a su sucesor el Excelentísimo señor don Pedro de Mendinueta año de 1796", en Relaciones de mando presentados por los gobernantes del Nuevo Reino de Granada. Eduardo Posada y Pedro Ibáñez (comps.). Bogotá: Imp. Nacional, 1910, 280-407.

Reichert, Rafal. "Entre la paz y la guerra, el gasto militar novohispano en la región del Gran Caribe (1609-1648)". Guerra y fiscalidad en la Iberoamérica colonial (siglos XVII-XIX)/Guerra e fiscalidade na Ibero-América colonial (séculos XVII$X I X)$. Angelo Alves y Ernest Sánchez Santiró (coords.). Minas de Gerais/México: Universidade Federal de Juiz de Fora/Instituto Mora, 2012, 39-64.

Sánchez Santiró, Ernest. "El gasto público de la Real Hacienda de Nueva España durante el siglo XVIII: estructura, dinámica y contradicciones". El gasto público en los imperios ibéricos, siglo XVIII. Ernest Sánchez Santiró (coord.). México: Instituto Mora/Conacyt, 2015, 36-62. 
Sánchez Santiró, Ernest. "Introducción”. El gasto público en los imperios ibéricos, siglo XVIII. Ernest Sánchez (coord.). México: Instituto Mora/ Conacyt, 2015, 10-11.

Sánchez de Tagle, Esteban. "Las reformas del siglo XVIII al gobierno; la ciudad, su hacienda, su policía, su ejército". Las reformas borbónicas, 1750-1808. Clara García (coord.). México: FCE /CIDE/Conaculta/México 2010/INEHRM/ Fundación Cultural de la Ciudad de México, 2010, 164-224.

Sánchez de Tagle, Esteban. "El monarca español y el gobierno de sus ciudades. La hacienda de la Ciudad de México". Formas de gobierno en México. Poder político y actores sociales a través del tiempo, vol. I. Víctor Gayol (coord.). Zamora: Colmich, 2012, 173-187.

Schaub, Jean. "Sobre el concepto de Estado". Historia Contemporánea, 28. (2004): 47-51.

Serrano Álvarez, José. “Apuntes para una metodología del estudio del gasto militar en Indias”. Temas Americanistas, 15. (2002): 75-89.

Serrano Álvarez, José. "Situados y rentas en Cartagena de Indias durante el siglo XVIII”. Temas Americanistas, 17. (2004): 58-78.

Serrano Álvarez, José. "Economía, rentas y situados en Cartagena de Indias, 17611800". Anuario de Estudios Americanos, 63. 2. (2006): 75-96.

Serrano Álvarez, José. "Política, reformas y economía militar en tiempos difíciles. Nueva Granada, 1770-1824”. Efectos del colonialismo borbónico en el virreinato del Nuevo Reino de Granada. Margarita Restrepo (ed.). Bogotá: Universidad del Rosario/Universidad Pontificia Bolivariana, 2018, 141-168.

Serrano Álvarez, José y Kuethe, Allan. "El situado mexicano y la Cuba borbónica". El secreto del imperio español: los situados coloniales en el siglo XVIII. Carlos Marichal y Johanna von Grafenstein (coords.). México: Colmex/Instituto Mora, 2012, 95-114.

Sokoloff, Kenneth and Zolt, Eric. "Inequality and the evolution of taxation", Economic Development in the Americas since 1500. Endowments and Institutions. Stanley E. Engerman and Kenneth L. Sokoloff. New York: Cambridge University Press, $2012,168-211$.

Solano, Sergio Paolo. "Historiografía sobre las relaciones entre las instituciones coloniales y los artesanos de Hispanoamérica a finales de la Colonia". Pensar la historia del trabajo y los trabajadores en América, siglos XVIII y XIX. Sonia Pérez Toledo y Sergio Paolo Solano (coords.). Madrid/Frankfurt: AHILA/ Iberoamericana/Vervuert, 2016, 17-58. 
Gasto fiscal e inversiones en mano de obra libre en Hispanoamérica. El caso de Cartagena...

Torres, Rafael. "El gasto público en la España del siglo XVIII”. El gasto público en los imperios ibéricos, siglo XVIII. Ernest Sánchez Santiró (coord.). México: Instituto Mora/Conacyt, 2015, 23-72.

Valle, Guillermina del. "Respaldo financiero de Nueva España para la guerra contra la Gran Bretaña, 1779-1783”. Guerra y fiscalidad en la Iberoamérica colonial (siglos XVII-XIX)/Guerra e fiscalidade na Ibero-América colonial (séculos XVII$X I X)$. Angelo Alves y Ernest Sánchez Santiró (coords.). Minas de Gerais/México: Universidade Federal de Juiz de Fora/Instituto Mora, 2012, 143-166.

Yun, Bartolomé. "Introducción. Entre el imperio colonial y la monarquía compuesta. Élites y territorios en la Monarquía Hispánica (ss. XVI y XVII)". Las redes del imperio. Élites sociales en la articulación de la monarquía hispánica, 1492-1714. Bartolomé Yun (dir.). Madrid: Marcial Pons/Universidad Pablo de Olavide, 2009, 11-35.

\section{Artículos de revistas}

Arévalo, Decsi y Rodríguez, Oscar. "La fiscalidad bajo un régimen de dominación colonial: el caso de la caja real de Cartagena 1738-1802". Anuario Colombiano de Historia Social y de la Cultura, 35. (2008): 19-64.

Barbier, Jacques y Klein, Herbert. "Las prioridades de un rey ilustrado. El gasto público bajo el reinado de Carlos III". Revista de Historia Económica, 3. 3. (1985): 473-496.

Betancur, Arturo. "La provisión de servicios en el puerto colonial de Montevideo: Alcances y limitaciones de una fuente local de riqueza". Anuario de Estudios Americanos, LIII. 2. (1996): 123-145.

Biangardi, Nicolás. "Producción rural y fiscalidad en el Río de la Plata durante el siglo XVIII”. Bibliographica Americana, 11. (2015): 52-68.

Celaya, Yovana. "Impuestos locales en nueva España: negociación y obra pública en el ayuntamiento de Veracruz en el siglo XVIII". Espacio, Tiempo y Forma, 27. (2014): 37-59.

Cuesta, Martín. "Impuestos imperiales: la caja real de Buenos Aires (1700-1800)". Temas de Historia Argentina y Americana, 14. (2009): 45-48.

Díaz, Carlos. "Hacienda pública en tiempos de guerra: la caja real de Santafé de Bogotá durante la reconquista de la Nueva Granada, 1816-1818". Fronteras de la Historia, 18. 1. (2013): 129-164.

Galarza, Antonio. "La fiscalidad en el Río de la Plata tardocolonial: un posible balance historiográfico a partir de las cajas reales". Bibliographica Americana, 11. (2015): 9-30. 
Gámez, Manuel. "Ingenieros militares y obras públicas. algunos ejemplos de Nueva Granada en el siglo XVIII". Ars Longa, 27. (2018): 134-136.

Garriga, Carlos. “Orden jurídico y poder político en el Antiguo Régimen”. Istor, 16. (2004): 13-44.

Garriga, Carlos. "Os limites do reformismo bourbônico: a propósito da administração da justiça na América español”. Almanack, 6. (2013): 38-60.

Hespanha, Antonio. "Una nueva historia política e institucional". Revista Mexicana de Ciencias Políticas y Sociales, 41. 166. (1996): 9-45.

Jara, Álvaro. "El financiamiento de la defensa en Cartagena de Indias: los excedentes de las cajas de Bogotá y de Quito, 1761-1802”. Historia, 28. (1994): 117-182.

Jumar, Fernando et al. "El comercio ultramarino y la economía local en el complejo portuario rioplatense, siglo XVIII”. Anuario del IEHS, 21. (2006): 235-254.

Laviana, María. “Excedente fiscal y defensa del imperio: El 'situado' de Guayaquil a Cartagena en el siglo XVIII”. Revista del CESLA, 11. (2008): 93-104.

Marchena, Juan. "La financiación militar en Indias: introducción a su estudio". Anuario de Estudios Americanos, XXXVI. (1979): 81-110.

Muñoz, Edwin. "Estructura del gasto y del ingreso en la Caja Real de Santafé, 18031815". Anuario Colombiano de Historia Social y de la Cultura, 37. 2. (2010): 45-85.

North, Douglass, Summerhill, William y Weingast, Barry. "Orden, desorden y cambio económico: Latinoamérica vs. Norte América". Instituciones y Desarrollo, 12-13. (2002): 9-59.

Pinto, José. "Impacto fiscal de las reformas borbónicas y del proceso independentista en la caja real y tesorería provincial de Antioquia 1750-1819”. Revista Uruguaya de Historia Económica, VI. 10. (2016): 9-23.

Pinto, José y Díaz, Carlos. "Fiscalidad en Popayán, 1750-1821”. Tiempo \& Economía, 3. 2. (2016): 33-54.

Reichert, Rafal. "El situado novohispano para la manutención de los presidios españoles en la región del golfo de México y el Caribe durante el siglo XVII". Estudios de Historia Novohispana, 46. (2012): 47-81.

Rodríguez, Oscar. "La Caja Real de Popayán”. Anuario Colombiano de Historia Social y de la Cultura, 15. (1987): 5-36.

Solano, Sergio Paolo. "Sistema de defensa, artesanado y sociedad en el Nuevo Reino de Granada. El caso de Cartagena de Indias, 1750-1810". Memorias, 10. 19. (2013): 92-139. 
Gasto fiscal e inversiones en mano de obra libre en Hispanoamérica. El caso de Cartagena...

Solano, Sergio Paolo. “Artesanos, jornaleros y formas concentradas de trabajo: el Apostadero de la Marina de Cartagena de Indias (Nuevo Reino de Granada) en el tránsito entre los siglos XVIII y XIX”. Theomai, 31. (2015): 79-105.

Solano, Sergio Paolo. "Pedro Romero, el artesano: trabajo, raza y diferenciación social en Cartagena de Indias a finales del dominio colonial". Historia Crítica, 61. (2016): 151-170.

Solano, Sergio Paolo. “Trabajadores, jornales, carestía y crisis política en Cartagena de Indias, 1750-1810”. Historia, LI. 2. (2018): 549-488.

Solano, Sergio Paolo. "El costo social de la república: los trabajadores de los sistemas defensivos de Cartagena de Indias, 1750-1850. Historia y Memoria, 18. (2019): 243-287.

Thul, Florencia. "Relaciones laborales en el sector de la construcción en el Montevideo tardo-colonial. La construcción de las fortificaciones y de la iglesia matriz, 17601808”. Revista Uruguaya de Historia Económica, VI. 10. (2016): 48-64.

Torres, Rafael. "Las prioridades de un monarca ilustrado o las limitaciones del estado fiscal-militar de Carlos III". Hispania, LXVIII. 229. (2009): 407-436.

Torres, Rafael. El precio de la guerra. El Estado fiscal militar de Carlos III (17791783). Madrid: Marcial Pons, 2013.

\section{Ponencias, tesis y otros}

Calderón, Andrés. Mirando a Nueva España en otros espejos. Cuatros ensayos sobre demografia y niveles de vida, siglos XVI-XIX. Madrid: tesis doctoral Universidad Complutense de Madrid, 2016. https://eprints.ucm.es/40711/1/T38176.pdf

Klein, Herbert. "Fiscalidad real y gastos de gobierno". Documento de trabajo 66, Serie Economía, 12. (1994).

Luque, Emilio. Ciudad y poder. La construcción material y simbólica del Montevideo colonial y sus imaginarios (1723-1810). Sevilla: CSIC/Diputación de Sevilla, 2007.

Pinto, José. Entre colonia y república. Fiscalidad en Ecuador, Colombia y Venezuela, 1780-1845. Bogotá: tesis doctoral-Universidad Nacional, 2014.

Sandrín, María E. La demanda de bienes y servicios para la Corona y la navegación ultramarina en el complejo portuario rioplatense y la dinamización de la economía regional, 1680-1810, tomo I. La Plata: tesis doctoral Universidad Nacional de La Plata, 2015.

\section{Publicaciones en internet}

http://realhacienda.colmex.mx/ 